\title{
Igneous differentiation by deformation
}

\author{
N. Petford ${ }^{1}$ - M. A. Koenders ${ }^{2} \cdot$ J. D. Clemens ${ }^{3}$
}

Received: 2 October 2019 / Accepted: 10 March 2020 / Published online: 20 April 2020

(c) The Author(s) 2020

\begin{abstract}
In a paper published in 1920, Bowen conceived of a situation where forces acting on a crystalline mesh could extract the liquid phase from the solid, and in doing so cause variations in chemistry distinct from the purely gravitational effects of fractional crystallisation. His paper was a call-to-arms to explore the role of deformation as a cause of variation in igneous rocks, but was never followed-up in a rigorous way. Inspired by this, we have developed a quantitative model showing how shear deformation of a crystallised dense magma $(\phi>70 \%)$ with poro-elastic properties is analogous to a granular material. The critical link between the mechanics and associated compositional changes of the melt is the degree to which the crystallising magma undergoes dilation (volume increase) during shear. It is important to note that the effect can only take place after the initial loose solid material has undergone mechanical compaction such that the grains comprising the rigid skeleton are in permanent contact. Under these conditions, the key material parameters governing the dilatancy effect are the physical permeability, mush strength, the shear modulus and the contact mechanics and geometry of the granular assemblage. Calculations show that dilation reduces the interstitial fluid (melt) pressure causing, in Bowen's words, "the separation of crystals and mother liquor" via a suction effect. At shear strain rates in excess of the tectonic background, deformation-induced melt flow can redistribute chemical components and heat between regions of crystallising magma with contrasting rheological properties, at velocities far in excess of diffusion or buoyancy forces, the latter of course the driving force behind fractional crystallisation and viscous compaction. Influx of hotter, less evolved melt drawn internally from the same magma body into regions where crystallisation is more advanced (auto-intrusion), may result in reverse zoning and/or resorption of crystals. Because dilatancy is primarily a mechanical effect independent of melt composition, evolved, chemically distinct melt fractions removed at this late stage may explain miarolitic alkaline rocks, intrusive granophyres in basaltic systems and late stage aplites and pegmatites in granites (discontinuous variations), as proposed by Bowen. Post-failure instabilities include hydraulic rupture of the mush along shear zones governed by the angles of dilation and internal friction. On the macro-scale, a combination of dilatancy and fracturing may provide a means to extract large volumes of chemically evolved melt from mush columns on short ( $<1000$ year) geological timescales.
\end{abstract}

Keywords Magma deformation $\cdot$ Dilatancy $\cdot$ Poro-elastic $\cdot$ Mush column

Communicated by Steve Reddy.

Electronic supplementary material The online version of this article (https://doi.org/10.1007/s00410-020-1674-3) contains supplementary material, which is available to authorized users.

N. Petford

nick.petford@northampton.ac.uk

1 University of Northampton, Northampton NN1 5PH, UK

2 Department of Civil, Maritime and Environmental Engineering, Faculty of Engineering and Physical Sciences, University of Southampton, Southampton SD17 1BJ, UK

3 Department of Earth Sciences, University of Stellenbosch, Private Bag X1, Matieland 7602, South Africa

\section{Introduction}

"It is not difficult to conceive of a distribution of forces in the heterogeneous surroundings of an igneous mass, such that locally the liquid might be sucked out of the crystalline mesh... such physical separation of two magmatic phases is the complement of chemical differentiation" (Bowen 1920).

It is more than a century since these words were written, and significant progress has been made in understanding the physics of melt segregation in the Earth. Movement of magmatic pore fluid (melt) within a solid crystalline matrix has been investigated quantitatively (e.g. McKenzie 1984; Scott and Stevenson 1986; Turcotte and Schubert 2002; 
Marsh 2002; Bachmann and Bergantz 2004; Solano et al. 2012; Bergantz et al. 2017) and experimentally (e.g. van der Molen and Patterson 1979; Tait and Jaupart 1992; Rutter and Neumann 1995, Renner et al. 2000; Rosenberg and Handy 2005; Kohlstedt and Holtzman 2009; Walte et al 2011; Quintanilla-Terminel et al. 2019). However, although representing a significant body of work, current melt segregation models differ from that conceived by Bowen in several important ways. First, the majority are formulated to deal with the important problem of extracting small-degree (generally $<<20 \%$ ) partial melts from the upper mantle or lower crust, where the relevant phase transition is from solid to liquid. As pointed out by Vigneresse et al. (1996), melting and crystallisation processes do not perfectly mirror each other; segregation models for melting and crystallisation require different initial formulations. Second, multiphase compaction models assume that buoyancy effects, coupled with viscous deformation of the granular matrix, drive the flow instability (segregation). Studies that take into account more complex matrix rheologies, including visco-elastic behaviour (e.g. Connolly and Podladchikov 1998), still rely on buoyancy-forced melt flow. This situation is quite different from Bowen's original idea of melt being 'sucked' out of a rigid, sparingly deformable matrix in an externally imposed stress field.

Complementary to this, the search for an efficient mechanism for the extraction of significant quantities of evolved melt in high level (sub-volcanic) silicic systems remains elusive (Lundstorm and Glazner 2016; Bachmann and Huber 2018). In contrast to the textbook idea of a liquid-filled magma chamber, a flurry of recent papers has promoted the idea (e.g. Marsh 2004) of crustal magma reservoirs as vertically extensive mush columns (Cashman et al. 2017; Jackson et al. 2018; Sparks et al. 2019). In these models, fractionation and compositional diversity is achieved mainly as a consequence of melt migration through a porous, viscously compacting matrix. According to Bea et al. (2005) and Berger et al. (2017), fractionation by deformation-driven filter pressing and compaction appears responsible for producing the mineralogical and chemical variations in some large intrusions. However, textural and microstructural evidence has raised doubts as to the efficacy of compaction in magmas as a mode of melt segregation in mafic intrusions (Holness et al. 2017). Holness (2018) reviewed the problem for silicic systems, arguing that the commonly invoked trio of viscous compaction, micro-settling and gas filter pressing (Anderson et al. 1984; Pistone et al. 2015) are themselves insufficient to cause melt segregation at rates comparable with erupted volumes of dacite and rhyolite (see also Bachmann and Huber 2018).

While there are undoubtedly many configurations in which the viscous approach is entirely apposite, we promote the idea that deformation due to external (non-gravitational) stresses applied to crystallising magma may provide another solution to the melt extraction conundrum, in both mafic and silicic magmas, at intermediate to high levels in the crust. Indeed, a theoretical framework, motivated by Bowen's appeal to differentiation by deformation, was set out by Koenders and Petford (2000) and developed further in a series of follow-up papers (Petford and Koenders 2003; Koenders and Petford 2005, 2007). In brief, our analytical model captures a dilation effect inherent in densely packed poro-elastic materials undergoing shear, that-importantly with respect to the current debate on melt segregationoccurs after compaction.

In this contribution, we begin by reviewing the important effect of dilatancy (pore volume increase) in deforming granular aggregates, and its historical context in petrology outside its practical origins in soil mechanics. Given that Bowen was also concerned to show that deformation could be important in producing chemical diversity in crystallising magmas, we describe quantitatively the link between the external strain field in the vicinity of the crystallising magma and associated compositional and thermal changes. Key details of the process including the contact mechanics between particles and the elastic properties of minerals comprising the deforming mush, are quantified. Melt flow rates and extraction times during shear are examined over a range of potential shear strain rates, from background tectonic to seismic events, and compared to estimates based on buoyancy forces. A novel aspect of this new work is the linkage made between the phase petrology of two component systems (e.g. plagioclase and olivine solid solutions) during advanced stages crystallisation and theoretical estimates of shear strength and conditions of failure of the crystal aggregate using Mohr diagrams. Finally, we comment on the applicability of the model to explain the large scale segregation of rhyolitic liquids in putative crustal magma reservoirs.

\section{The neglected importance of dilatancy in sheared crystalline mush}

A key concept in what follows is that a solidifying magma can be treated as a dense granular material that will dilate under an imposed shear stress. While this should be noncontroversial, reference to dilatancy in the literature as a fractionation mechanism in igneous rocks is scarce. Of the various melt-crystal segregation mechanisms put forward over the last 100 years, filter pressing (see Propach 1976), comes closest, and while the author recognised that "every compression must be accompanied by a dilation, which creates room for the filtrate", questioned whether a satisfactory model could be found to quantify it. 
In a seminal paper, Mead (1925) proposed that densely packed magma suspensions, in which crystal contents exceed $50 \%$, should be considered as granular masses. Following Bowen (1920), Emmons (1940) put forward the idea that dilatant rifting of a dense crystal mush would draw melt into 'voids' (interstices), a process referred to subsequently by Carmichael et al. (1974) as 'auto-intrusion'. More recently, Smith (1997) proposed shear thickening and dilatancy as a mechanism to explain deformation textures in crystal-rich volcanic rocks. The basic idea, that magma with a substantial fraction of solids is analogous to a fluid-saturated granular mass, opens up a link to the fundamental observation, first made by Reynolds (1885), that dilating granular materials expand in bulk with change of shape. Corresponding shear-induced volume changes in the granular matrix then create regions of lowered pore pressure that draw fluid towards them, resulting in macroscopic fluid flow within the deforming assemblage.

Despite however its conceptual simplicity and appeal, it has proved non-trivial to capture dilatant behaviour quantitatively in crystallising magma. A possible way forward was proposed by Koenders (1997) and Koenders and Petford (2000), who used a mathematical model based on the equations of linear poro-elasticity first proposed by Biot (1941). Following Mead (1925), the relevant differential equations were modified to take into account the effects of shearinduced dilatancy in magmas by coupling the volumetric strain to the deviatoric (shear) stress in the granular matrix. This approach thus differs fundamentally from compaction models (McKenzie 1984) in which the granular matrix is defined as a dense, viscous fluid with no inherent strength.

The relationship between compaction and dilatancy and their relationship to volumetric strain is shown in Fig. 1 for initially loose and densely packed granular materials. In passing it should be noted that Biot's equations have immense practical engineering applications for dealing with porous rock and dense sands undergoing changes in fluid pressure and stress (e.g. Engelder 1993; Hillis 2000). While magmas may be considered exotic in comparison with soils and hydrocarbon reservoirs, they nonetheless will obey the same general laws of physics as any saturated granular mass exposed to shearing forces. This is borne out by the experimental work of van der Molen and Paterson (1979) on partially molten granite where dilation effects were observed in conjunction with strain-dependent movement of the melt phase (see also Renner et al. 2000) and concave-upwards stress-strain curves (Fig. 1). Reynolds dilatancy is also seen in deforming alloys at high crystallinity, analogous to that proposed here for magmas (Gourlay and Dhale 2007; Kareha et al. 2017). These experiments verify the granular dilatancy effect is real in high-temperature mixtures, and confirm the applicability of the relevant analysis in soil mechanics to partially molten systems more generally.

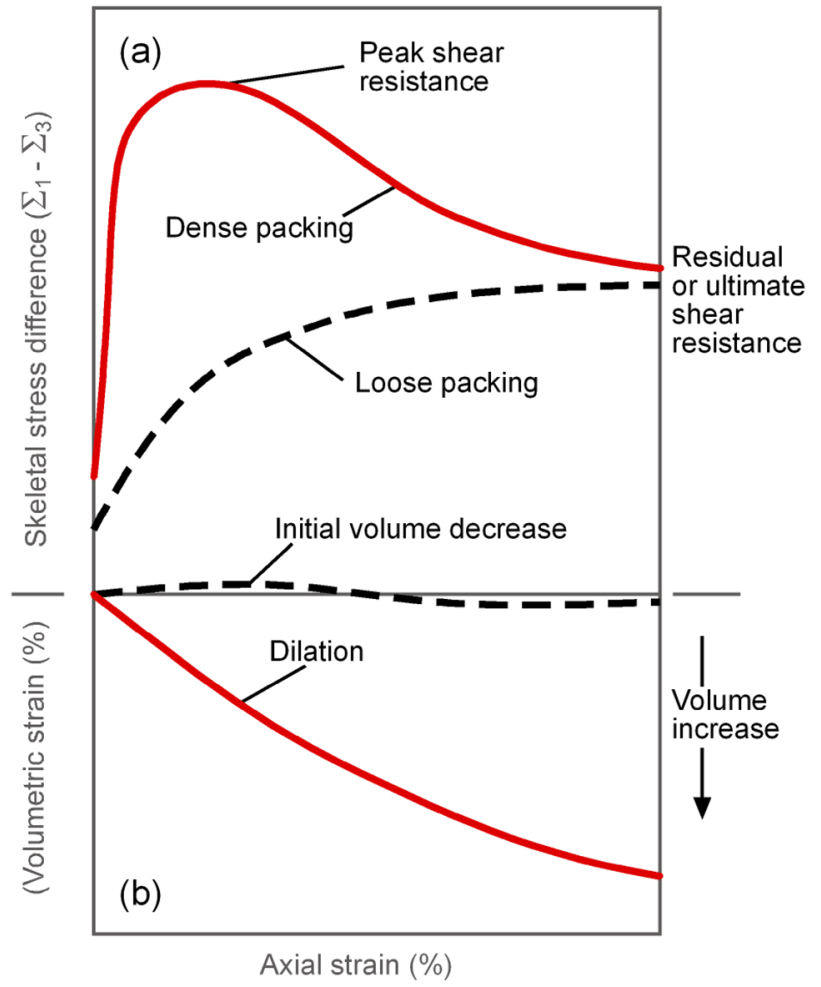

Fig. 1 Illustration of the changes in the difference of principal skeletal stresses and volume strain for an initially loose packed compacting granular layer (dashed line) that subsequently undergoes dilation due to shear at high particle contents. By analogy, in initially compacted magmas where the packing density exceeds the critical melt fraction, further deformation can only take place through dilatancy (red curve). Characteristic (concave-upwards) curves for a densely packed medium (a), and corresponding increase in volumetric strain (b) during shear have been observed in deformation experiments of partially molten rock and metal alloys at high solid fractions (van der Molen and Paterson 1979; Kareha et al. 2017), consistent with Reynolds dilation in these materials

\section{Poro-elastic theory}

Poro-elasticity provides a general theory for describing the coupled deformation of a solid (elastic or elasto-plastic and, in some cases, elasto-viscous) granular matrix with changes in intergranular pore fluid pressure. The theory assumes that porosity is connected but does not require an explicit description of the matrix geometry. As such it is well suited to the study of deformable porous media, including magma, undergoing shear. Koenders and Petford (2000) first showed theoretically the effect of shearing a poro-elastic magmatic layer comprising a mixture of solid grains (crystals) and pore fluid (melt) in the ratio 70:30\%. In the model, granular dilatancy increases the pore space such that the locally reduced pressure sucks fresh melt into the deforming layer, matching closely the situation envisioned by Bowen (1920) and Emmons (1940). 
Cast in terms of consolidation of a compressible fluid moving in a porous magma mush with a one-dimensional, position-dependent permeability $k(y)$, the governing equation is

$\frac{\partial}{\partial y}\left(k(y) \frac{\partial p}{\partial y}\right)=n \beta \frac{\partial p}{\partial t}+\frac{\partial \dot{v}}{\partial y}$

where $\dot{v}$ is the vertical displacement velocity of the solids, $n$ the porosity (melt fraction) and $\beta$ is the melt compressibility, taken as 0 . Note that while the latter is important in $\mathrm{H}_{2} \mathrm{O}$-rich magmas (e.g. Manga et al. 1998), it is a secondorder effect that can be incorporated subsequently. The solution to Eq. (1) depends largely on the rheological properties of the deforming magmatic mush, in particular the dilatant moduli (see below), which are not currently well known for magmas, and the physical permeability $(k)$.

The effect will not happen instantaneously during loading. An estimate of the time to dilation $(\Gamma)$ is obtained by calculating how long it takes the material to reach the isotropic pre-stress level under the imposed shear strain rate. This depends on the stiffness parameters of the mush assembly, which in turn are obtained from the contact mechanics of the participating minerals. It is given by

$\Gamma \approx \frac{1}{\varsigma}(Q \Sigma)^{2 / 3} \frac{1}{\frac{\partial \dot{u}}{\partial y}}$,

where $Q$ and the ambient mean skeletal stress, $\Sigma$ (the stress associated with inter-particle forces), are variables that define the contact stiffness of the assemblage (see Appendix Eqs. 23 and 24); $\dot{u}$ is the horizontal displacement velocity of the solids and $\varsigma$ a constant of order unity.

Key to quantifying the suction effect is to couple the transport properties of the mush to changes in interstitial pore fluid pressure during shear (Petford and Koenders 2003). As such, particular focus is applied to the limiting state, which is assumed to persist under continued shear. After an initial change from the point when the shear strain rate is first applied, the long-term excess pore pressure $p(y)$ settles to a position-dependent value that is proportional to the applied shear stress rate $\dot{c}_{0}$. Imposing boundary conditions that require the excess pressure to vanish at the bottom of the layer $(y=-H)$ and demand no-flow at the top (fluid pressure gradient zero at $y=0)$, the excess pore pressure is equal to

$p(y)=R \dot{c}_{0} \frac{H^{2}-y^{2}}{2 k \theta}$,

where $H$ is the mush layer thickness and $y$ the vertical position in the layer. Furthermore, there are two material constants $R$ and $\theta$ that describe the mechanical behaviour of the granular assembly. These depend on the state that the material is in. Under continued shear, it evolves quite drastically from an assumed isotropic (more or less elastic) state to one in which the ratio of the principal stresses reaches a limiting value. In this process, the two parameters change as follows: $R:$ from $0 \rightarrow \frac{R_{\mathrm{s}}+1}{R_{\mathrm{s}}-1}$ and $\theta:$ from $A_{2222}^{(e)} \rightarrow G$, where $R_{\mathrm{s}}$ is the principal stress ratio in the limiting state, $A_{2222}^{(e)}$ is the principal modulus in the elastic state and $G$ the shear modulus in the limiting state. Analysis of the moduli in the limiting state is carried out in the Appendix.

Finally, with boundary conditions following Petford and Koenders (2003), the flow rate into the medium $(q)$, in the limiting state is

$q=\frac{A_{2222}\left(\Sigma_{1} / \Sigma_{3}+1\right)(1-\delta)}{8 G(G n \beta+1)} H \frac{\partial \dot{u}}{\partial y}$.

Again, key parameters are the layer thickness and the horizontal shear strain rate $\partial \dot{u} / \partial y ; \Sigma_{1}$ and $\Sigma_{3}$ are the major and minor principal skeleton stresses. Because dilatancy and the pressure changes driving fluid flow are independent of gravity, there is no buoyancy term. Accordingly, it is the dilatancy parameter $(\delta)$, that governs the rate of movement of melt in and out of the deforming mush - a significant point of difference between the model here and existing mechanisms for solid-melt segregation in igneous systems. Thus, when $\delta<1$ melt is squeezed out, but when $\delta>1$ melt is drawn in, conforming exactly to Bowen's proposed suction effect.

\section{An explanation of the moduli and contact mechanics governing mush dilation}

The solution to Eq. (4) also requires information about the skeletal stress ratio $\left(\Sigma_{1} / \Sigma_{3}\right)$ and a ratio of the incremental stiffness moduli, in particular $A_{2222} / G$ conforming to the stiffness tensor of the mush during applied shear.

Briefly, this ratio can be derived from the estimated angular contact distribution and contact stiffness of the granular mush (see Appendix). Particles in contact under load transmit stress, and knowledge of point and assembly dynamics comprise a branch of engineering called contact mechanics (Johnson 1985). The contact stiffness can be obtained from Hertzian analysis of touching spherical or cylindrical surfaces with varying roughness (e.g. Shi and Polycarpou 2005). This requires data on the elastic properties of each mineral comprising the mush assemblage, notably the Young's modulus $(E)$, shear modulus $(G)$ and Poisson's ratio $(\nu)$, all of which are well constrained for common rock-forming minerals over a wide range of P-T conditions. Other interfacial parameters include the grain size and, critically, the average number of contacts per particle. This coordination number $Z$ (Fig. 2a) provides an important 
(a)

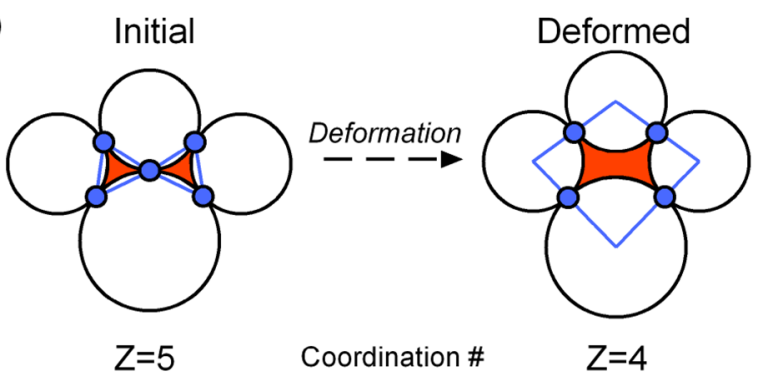

(b)

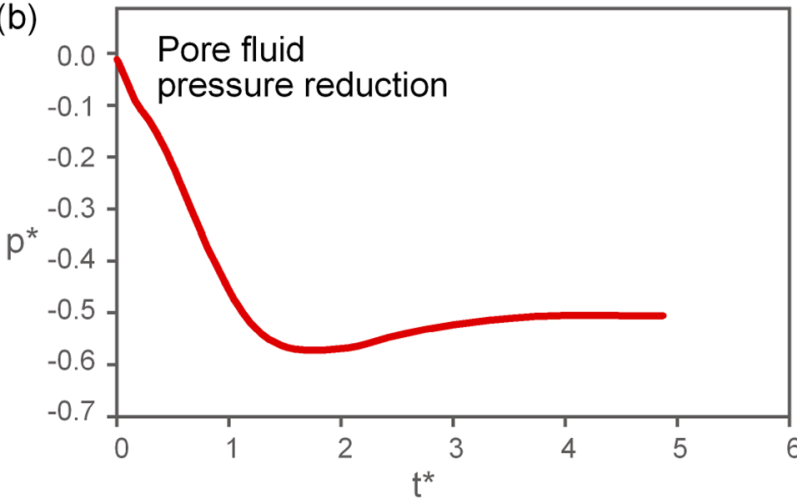

Fig. 2 Mechanical behaviour of congested magma during shearinduced dilation. a Deformation and volume expansion reduces the number of crystals that share a point contact ( $Z$ ) from 5 to 4 and increases the contact force on individual grains (Appendix, Eq. 21). b Volume expansion of the granular framework lowers the pore fluid (interstitial melt) pressure $p^{*}$ (shown here in non-dimensional form) from its initial equilibrium value of 0 at $t^{*}=0$, potentially sucking in melt from further afield, at a rate proportional to the thickness of the deforming region and rate of loading

link between the internal topology of the deforming crystal mush and the stress distribution, with a volume increase during dilatancy resulting in lower coordination numbers (the reverse is true for compaction). As $Z$ reduces, individual grains take more load, offset somewhat by increasing crystal content. Knowledge of how $Z$ evolves during crystallisation may in future be acquired by, for example, numerical simulations in the magmatic case, but can be explored analytically in the model. Figure $2 b$ shows the (scaled) distribution of the dimensionless excess pore fluid pressure $p^{*}$ as a function of the scaled time, $t^{*}$. The significant feature here is the rapid, early decrease in the excess (negative) pore pressure, which then settles down asymptotically to a long-term reduction. This aspect has been reported in detail by Petford and Koenders (2003). Note that while the reduced pore fluid pressure stays constant, the skeletal stress will increase, a consequence of which is that at some point the mush will fail (Emmons 1940). The potential implications for this are described later. Derivations of the relevant moduli included in the contact mechanics, are given in the Appendix.
In summary, Eqs. (1-4) open up a way to explore quantitatively the effects of deformation on the segregation velocity of silicic melts in a dilating mush, and compare these to rates obtained from compaction theory. Importantly, the shear strain rate is a free variable that can be set to background (plate) tectonic rates or benchmarked against other values of interest in excess of that, for example local strain caused by intrusion of magma pulses into a crystallising reservoir of some specified dimension. These ideas are explored in more detail in the sections that follow.

\section{Stress and shear strain rates}

An additional motivation for this work is to understand better the aggregate mechanical properties of mushy layers during dilatancy over a range of loading conditions, up to and including failure. Two examples are considered, (1) stress caused by overburden, and (2) a local skeletal stress associated with the inter-particle contact forces due to buoyancy in the magma. We begin by estimating the state of stress in a mush layer at equilibrium, located $1 \mathrm{~km}$ below the Earth's surface. The total vertical (lithostatic) stress for an overburden density of $3000 \mathrm{~kg} \mathrm{~m}^{-3}$ is c. $30 \mathrm{MPa}$ in the magma layer (e.g. Jaeger, 1969). The vertical skeletal stress $\left(\Sigma_{1}\right)$, either at the base or the roof of a mush layer, depending on the sign of the density contrast, equals $\Delta \rho g H / 2$ (Petford and Koenders 2003). For a magma with a density contrast $\Delta \rho=300 \mathrm{~kg} \mathrm{~m}^{-3}$ between melt and solid (e.g. Sparks et al. 2019), and arbitrary layer thickness $H=100 \mathrm{~m}, \Sigma_{1} \simeq 0.15 \mathrm{MPa}$.

The skeletal stress relates also to the internal properties of the magma layer. In the examples that follow, the particle stiffness is defined using published values of the relevant elastic constants for the assemblage under consideration. One nuance in the model is the ability to 'tune' the mush such that the elastic constants reflect as closely as possible magma mineralogy and phase petrology. For example, a plagioclase-dominated mush at $1200{ }^{\circ} \mathrm{C}$ with an average composition of $\mathrm{An}_{36}$ (Andesine) has a Young's Modulus $(E)$ and Poisson's ratio $(\nu)$ of $92 \mathrm{GPa}$ and 0.272 , respectively. For olivine (Fo 90\%), suitable values for $G$ and $E$ are $70 \mathrm{GPa}$ and $200 \mathrm{GPa}$ (Table 4 in Appendix).

Finally, as the dilatant effect requires an external source of deformation, three shear strain rates are used to reflect the general magnitude of deformation in the continental crust: (1) $10^{-14} \mathrm{~s}^{-1}$ corresponding to background tectonic strain, (2) a higher rate of $10^{-7} \mathrm{~s}^{-1}$ derived by Rust et al. (2003) from deformed bubbles in obsidian as a benchmark for (silicic) magma emplacement in subvolcanic environments and, for completeness, (3) loading from seismic activity (set arbitrarily to $10^{1} \mathrm{~s}^{-1}$ ). 


\section{Results}

\section{Time to dilatancy $(\Gamma)$}

Dilation requires a change in the material properties of the mush in response to shear. Order-of-magnitude estimates for the time $\Gamma$ to dilation from Eq. (2) are shown in Table 2 for each deformation régime (lithostatic overburden, $\Sigma_{o}$ ) and skeletal stresses caused by buoyancy $\left(\Sigma_{b}\right)$, for a mineral assemblage corresponding to a generic mafic and silicic mush. Time to dilatancy is shortest where local (skeletal) stresses dominate, with mafic mushes dilating faster than silicic ones. Results show that for tectonic loading, the material goes into dilatant mode on timescales of $10^{2}$ to $10^{4}$ years. For all cases, at loading rates associated with magma emplacement $\left(10^{-7} \mathrm{~s}^{-1}\right)$, the dilatant effect would activate on timescales $<24 \mathrm{~h}$. During an earthquake, dilatancy is practically instantaneous.

\section{Pore fluid pressure reduction during dilation}

We now examine changes in pore (melt) fluid pressure and melt flow rates in dimensional form. First, we estimate the physical permeability. For a mean grain size $(d)$, the order of magnitude permeability is $k=d^{2} n^{3} \gamma / \eta$, where $\gamma$ is the tortuosity (e.g. Ghanbarian et al. 2013). Note this expression differs from the geometrical permeability (e.g. McKenzie $1984)$ in that it includes the viscosity $(\eta)$ of the fluid (melt) phase. Thus, the physical permeability range of a mush comprising basaltic melt with a viscosity of $10^{2} \mathrm{~Pa} \mathrm{~s}$ is $\mathrm{c}$. $10^{-10}-10^{-9} \mathrm{~m}^{2} \mathrm{~Pa}^{-1} \mathrm{~s}^{-1}$ and for a rhyolitic one $\left(\eta=10^{5} \mathrm{~Pa} \mathrm{~s}\right.$, Clemens and Petford 1999) is $10^{-13}-10^{-12} \mathrm{~m}^{2} \mathrm{~Pa}^{-1} \mathrm{~s}^{-1}$, with other variables from Table 1 . The role of viscosity in the flow of wet granular materials is examined in detail by Huang et al. (2008). Changes in (excess) pore pressure in the limit can now be found from Eq. (3). The position-dependent pressure drop in the melt phase due to dilation is greatest in the silicic mush for all given rates of shear strain (Fig. 3), a compositional effect first described by Petford and Koenders (2003). Estimates of $p(y)$ gained this way are used later to help constrain changes in effective skeletal stress as the mush undergoes deformation.

\section{Melt flow rates}

Figure 4 shows estimates of melt flow rates using Eq. (4), with variables as above (see also Table 1), as a function of shear strain rate. Values range widely, from c. $10^{-15} \mathrm{~m} \mathrm{~s}^{-1}$ to $10^{-4} \mathrm{~m} \mathrm{~s}^{-1}$, depending upon the layer thickness and the dilatancy ratio. Slowest segregation velocities correspond to deformation at background (plate tectonic) rates and overlap with those typical for compacting silicic mushes (Sparks et al. 2019). As the rate of loading increases, so does the melt flow velocity in the dilating mush. At intermediate shear strain rates $\left(\right.$ c. $\left.10^{-10} \mathrm{~s}^{-1}\right)$ segregation rates at the upper end exceed $4 \mathrm{~m}$ year ${ }^{-1}$, several orders of magnitude faster than for compaction, and in the range reported by Pistone et al. (2015) for gas filter pressing (0.6-6 myear $^{-1}, \phi=0.75$ ). For assumed emplacement-related strains $\left(\right.$ c. $\left.10^{-7} \mathrm{~s}^{-1}\right)$, melt flow rates exceed $10^{-4} \mathrm{~m} \mathrm{~s}^{-1}\left(>1 \mathrm{~km} \mathrm{year}^{-1}\right)$. At these velocities, melt segregation on a pluton scale appears feasible, especially so if the shear strain rate were increased still further. Scaled up, this could allow for extensive silicic melt segregation on decadal timescales (see discussion section).

\section{Deformation of mushy layers}

To better visualise the deformation process, we have constructed illustrative Mohr diagrams and a Griffith-Coulomb failure envelope for a hypothetical mush, both at rest and during deformation, for the limiting case where the skeletal stresses are buoyancy related $\left(\Sigma_{b}\right)$. The latter requires information about the cohesion and tensile strength of the mush, along with relevant values for the elastic properties of the matrix appropriate for the composition in hand. In this example, we assume the mush is mafic and comprised of $80 \%$ olivine and $20 \%$ interstitial melt with a viscosity of $10^{2} \mathrm{Pas}$.

A description of the linear failure envelope in its simplest form reads $\tau^{\prime}=c+\Sigma \tan \phi_{\mathrm{C}}$, where $\phi_{\mathrm{C}}$ is the Coulomb angle of friction, a measure of a material's resistance to an applied shearing skeletal stress $\left(\tau^{\prime}\right)$ under an isotropic skeletal stress $(\Sigma)$. In light of scant experimental values for the angle of friction in dilating magma, we have assigned a value of $30^{\circ}$, one justification being it lies midway between the range for most granular materials that have been measured for this property (e.g. Bell 2007). The constant $c$ is the cohesion. This value is zero for dry granular materials, but Shaw (1980) put forward the notion that there may be a small nonzero value in magmas analogous to a yield strength. Following Ryerson et al. (1988), we thus estimate a cohesion of c. $4 \mathrm{kPa}$ for a crystal fraction of 0.8 .

Finally, an estimate of the tensile strength $(-K)$ of the magma is needed. While exact values remain qualified by the strain rate regime, rough estimates of the tensile strength of partially molten basalt with $80 \%$ crystals lie in the range $10^{4}-10^{6} \mathrm{~Pa}$ (e.g. Shaw 1980). Marsh (2002) provides an estimate of the tensile strength of a solidification front in the range $10^{2}-10^{8} \mathrm{~Pa}$, with strength increasing with crystal fraction. Geometrically, both the angle of friction and the tensile strength contribute to the slope of the Griffith-Coulomb failure envelope, meaning it is possible to obtain one from knowledge of the other. In this example, using the value for cohesion above gives an order of magnitude estimate of $2 \times 10^{3} \mathrm{~Pa}$ for the tensile strength, comparable with lower 
Table 1 List of symbols, numbers in brackets refer to values used in text

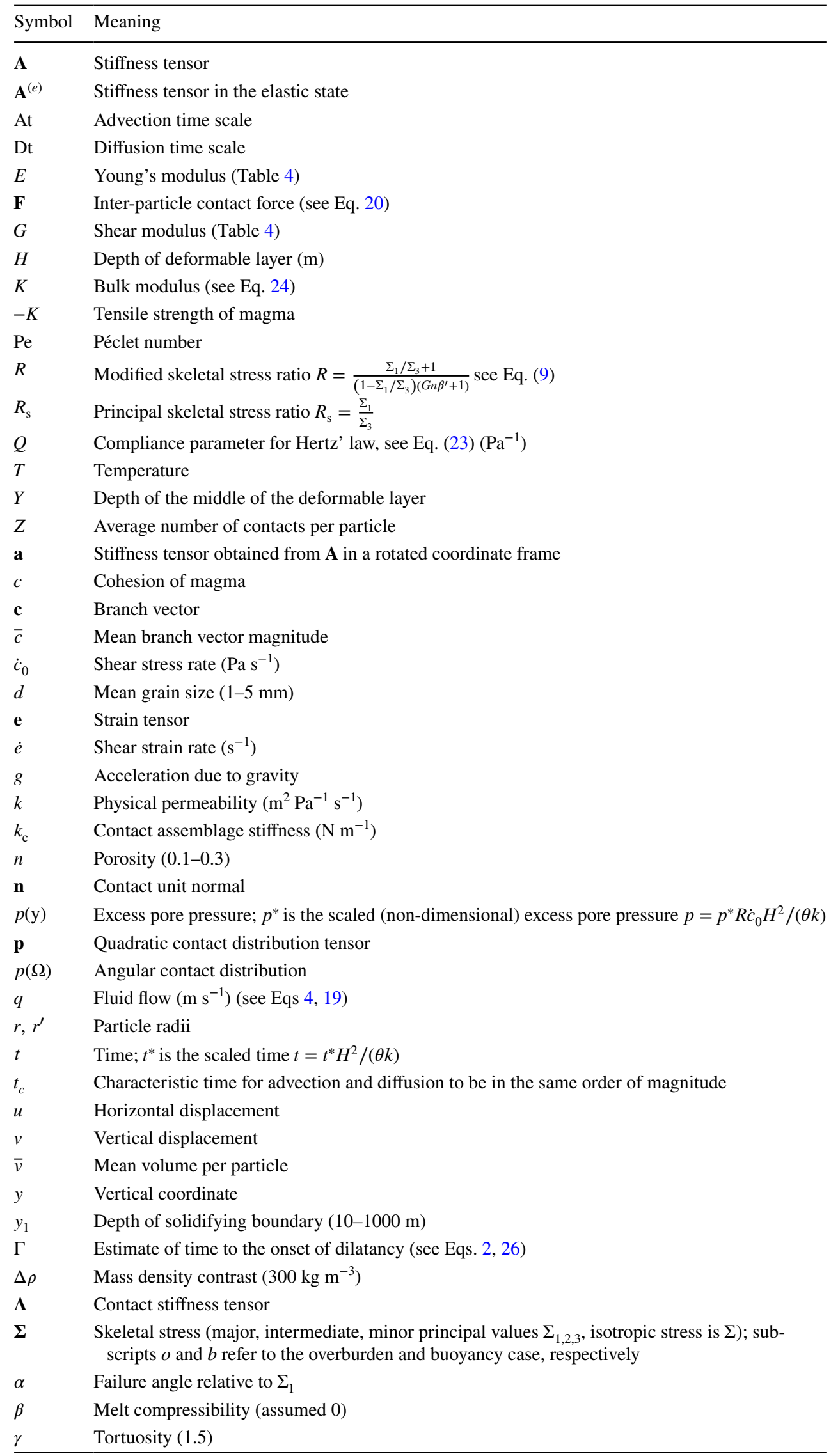


Table 1 (continued)

\begin{tabular}{ll}
\hline Symbol & Meaning \\
\hline$\delta$ & Dilatancy parameter in a biaxial cell test $\delta=A_{2211} / A_{2222}$ \\
$\phi$ & Solids volume fraction $(0.7-0.9)$ \\
$\phi_{\mathrm{C}}$ & Coulomb friction angle $\left(30^{\circ}\right)$ \\
$\kappa$ & Thermal diffusivity \\
$\lambda_{1}$ & Thermal constant for Stefan problem (0.6) \\
$\lambda^{(n)}, \lambda^{(t)}$ & Normal and tangential contact stiffness coefficients \\
$\theta$ & Shear modulus in end state \\
$\varsigma$ & Constant of order unity \\
$\eta$ & Interstitial melt viscosity (basalt $=10^{2}$ Pa s, Rhyolite $=10^{5}$ Pa s) \\
$\nu$ & Poisson's ratio (Table 4) \\
$\rho$ & Mass density \\
$\sigma$ & Total stress tensor (major, intermediate, minor principal values $\sigma_{1,2,3}$, isotropic value $\sigma$ ) \\
$\tau^{\prime}$ & Skeletal shear stress \\
\hline
\end{tabular}

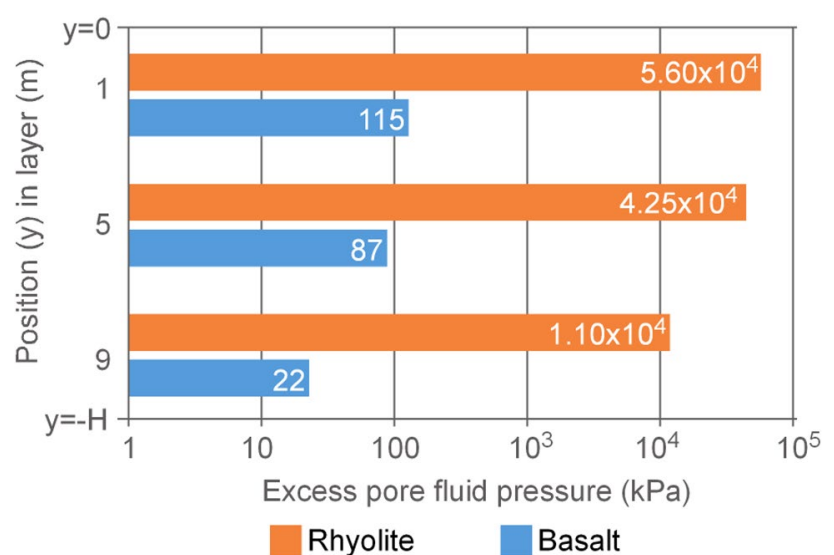

Fig. 3 Secular changes in excess (negative) pore fluid pressure $p(y)$ from Eq. (3) for a shear strain rate of $10^{-10} \mathrm{~s}^{-1}, \phi=0.8$ and $d=5 \mathrm{~mm}$. Mush composition is expressed via the interstitial melt viscosity $(\eta)$ in the physical permeability (basalt, $\eta=10^{2} \mathrm{~Pa} \mathrm{~s}$, rhyolite $\eta=10^{5} \mathrm{~Pa} \mathrm{~s}$, Table 1), and relevant elastic constants for the corresponding solid phase (olivine, $G=70 \mathrm{GPa}$ ), plagioclase ( $G=34 \mathrm{GPa}$, Table 4 ). The drop in excess pore pressure is position-dependent (top of layer, $y=0$ ), and decreases in magnitude downwards for both compositions. Excess pressure is greatest in the higher viscosity (rhyolitic) melt. $H=10 \mathrm{~m}$

end values reported in the literature for basaltic magmas (Marsh 2002).

The resulting family of Mohr circles is shown in Fig. 5. Several points of interest relevant to the deformation of congested magma emerge from the model analysis. First, it is noteworthy how close the static magma, with a differential stress of c. $100 \mathrm{kPa}$, is to failure, implying only a relatively minor perturbation to the stress state could result in instability (Fig. 5a). It is well known that pore fluid pressure $(p)$ exerts a fundamental control on rock and soil failure (Terzaghi 1943), through the skeleton stress $(\Sigma)$ where

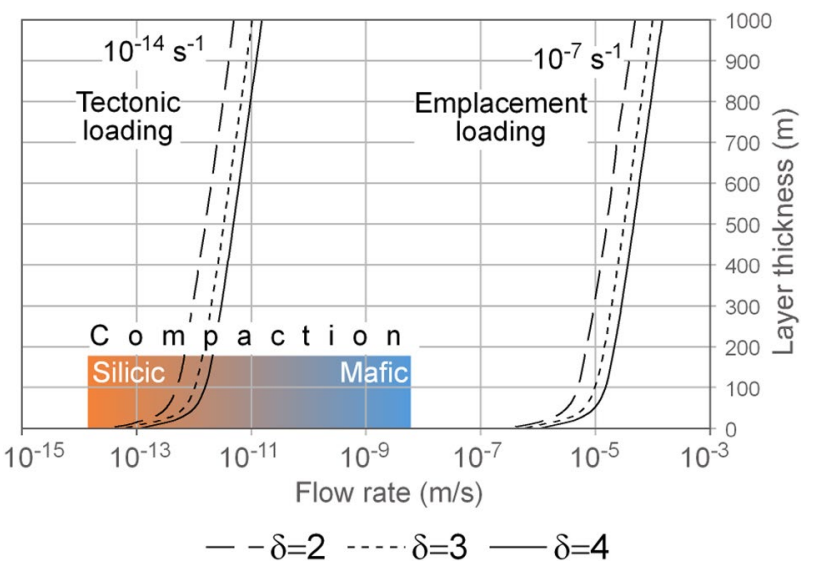

Fig. 4 Melt flow rates for strain rates corresponding to tectonic background and magma emplacement as a function of the positive dilatancy ratio $(\delta=2,3,4)$, calculated from Eq. 4 with $\phi=0.8$ and a stress ratio of 3. Layer thickness $0-1000 \mathrm{~m}$. Flow velocities increase with higher strain rates for all values of $H$ and $\delta$. Shaded area shows the range in compaction velocities and compaction lengths for matrix porosities of 0.01-0.3 and melt viscosities of $1-10^{5} \mathrm{~Pa} \mathrm{~s}$ (Sparks et al. 2019, Table 2)

$\Sigma=\sigma-p$. A familiar cause of hydraulic failure during fluid-rock interaction occurs when an increase in fluid pressure moves the Mohr circle left to intersect the failure envelope. However, during dilatancy, the opposite happens. This is because volumetric strain in the solid framework leads to a reduction in excess pore (melt) pressure (Eq. 3 and Fig. 3), meaning that the effective (skeletal) stress increases, moving the Mohr circle away from the failure envelope (Fig. 5b). As the change in excess pore pressure scales with melt viscosity (Fig. 3), the effective stress will be consistently higher for silicic magmas due to the greater change in excess fluid pressure during dilation. We note with interest comparable behaviour in hydrocarbon reservoirs as the fluid reservoir 
Table 2 Summary of timescale to dilation $(\Gamma)$ in a deforming magma mush of varying composition for three shear strain rates corresponding to plate tectonic, magma emplacement and earthquake loading rates, calculated from Eq. 2

\begin{tabular}{llllll}
\hline Shear strain rate & $\Gamma \Sigma_{b}$ Silicic & $\Gamma \Sigma_{b}$ Mafic & $\Gamma \Sigma_{o}$ Silicic & $\Gamma \Sigma_{o}$ Mafic & Units \\
\hline $\begin{array}{l}\text { Tectonic } \\
10^{-14} \mathrm{~s}^{-1}\end{array}$ & 550 & 460 & $1.8 \times 10^{4}$ & $1.5 \times 10^{4}$ & Years \\
$\begin{array}{l}\text { Emplacement } \\
10^{-7} \mathrm{~s}^{-1}\end{array}$ & 0.48 & 0.4 & 16 & 14 & Hours \\
$\begin{array}{l}\text { Earthquake } \\
10^{1} \mathrm{~s}^{-1}\end{array}$ & $2 \times 10^{-5}$ & $1.5 \times 10^{-5}$ & $6 \times 10^{-4}$ & $5 \times 10^{-4}$ & Seconds \\
\hline
\end{tabular}

The elastic constants of a mix of mineral types are chosen to reflect silicic (rhyolitic) and mafic (basalt) compositions, with Albite $\left(\mathrm{An}_{10}\right)$ and quartz for the silicic case and plagioclase (Labradorite $\left.\mathrm{An}_{56}\right)$ and pyroxene (augite) for the mafic one. Values used are given in Table 4. The stress regime in the mush relates to two cases, buoyancy $\left(\Sigma_{b}\right)$ and overburden $\left(\Sigma_{o}\right)$ with $\varsigma \approx 1$ (Table 1). In both cases time to dilatancy is fastest for mafic compositions, reflecting the elastic constants of the (slightly stiffer) minerals comprising the skeletal matrix becomes progressively depleted during extraction (e.g. Hillis 2000). It is similar also the effect seen in the experiments of van der Molen and Paterson (1979), where matrix strength increases temporarily in a processes called dilatancy hardening (see also Renner et al. 2000).

However, the reduction in excess pore fluid pressure does not mean that the mush will not fail at some later time as dilation continues. Our mathematical analysis, which is critically sensitive to the boundary conditions, does not contain an assessment of the granular (skeletal) stress ratio as it evolves, which, unlike the pore fluid pressure, will continue to increase with time. It is thus reasonable to assume that failure will occur at some stage as deformation proceeds. Again, by recourse to petroleum engineering, it is well documented that during depletion, the differential stress goes up as the pore fluid pressure drops (Hillis 2000). In these coupled models, consistent with the poro-elastic nature of the matrix, the vertical stress remains largely unaffected by changes in pore pressure, whereas the minimum horizontal stress reduces by up to $70 \%$ of the pressure drop in the fluid. This effect is simulated in Fig. 5c for the dilatant case by reducing $\Sigma_{3}$ until the Mohr circle intersects the failure envelope. This required change in differential stress $\Sigma_{1}-\Sigma_{3}$ is c. $25 \%$ of the initial isotropic stress. Following convention (Hobbs et al. 1976), where $2 \alpha=60^{\circ}$, the orientation of the failure plane lies at $30^{\circ}$ to the major principal skeletal stress direction, similar to angles reported from experiments elsewhere (e.g. Zimmerman and Kohlstedt 2004). In contrast, field observations on syn-kinematic leucosomes related to viscous compaction record orientations at much higher angles to the assumed maximum compressive stress (Weinberg et al. 2015). This difference in orientation might help tell apart the mechanical origin of brittle-like structures in igneous rocks thought to have formed in the magmatic state.

Finally, grain shape plays an important role. Konishi et al. (1982) have shown experimentally that the magnitude of the dilatancy effect is affected by the degree to which grain shape deviates from perfect sphericity. It also depends on the bedding angle (the angle between the major principal skeletal stress and the mean orientation of the particles), the impact on the dilatancy ratio is relatively modest $(<20 \%)$; the impact on the value of the stress ratio at failure is more pronounced and may be as large as a factor of two.

In summary, while acknowledging this analysis is hypothetical, it shows how dilation, rupture and the material properties of magma mushes more generally (e.g. Karlstrom et al. 2012) have important consequences for magma differentiation and melt extraction on crustal scales. The implications of this, including possible microstructure formation in the matrix and mesoscale drainage of compositionally distinct melts away from sites of deformation, are developed in more detail below.

\section{Comparison with diffusion rates}

To recap, shearing and dilatancy in a mush sets up fluid motions with a velocity $(q)$ proportional to the rate of shear strain (Eq. 4). How do the resultant fluid flow velocities compare with other common transport mechanisms such as thermal and chemical diffusion? A simple way to illustrate the relative importance of heat transport is via the Péclet number $\mathrm{Pe}=q H / \kappa$ where $\kappa$ is the thermal diffusivity, ranging from c. $0.35 \mathrm{~mm}^{2} \mathrm{~s}^{-1}$ in basaltic melts to $0.5 \mathrm{~mm}^{2} \mathrm{~s}^{-1}$ in silicic ones (e.g. Hofmeister et al. 2009). This is estimated in Fig. 6. At tectonic rates, induced melt flow is slower than thermal diffusion in both basaltic and rhyolitic melts $(\mathrm{Pe}<<1)$. Only where the shear strain rate approaches, or exceeds, inferred magma emplacement rates does Pe exceed unity. This introduces the idea, developed in more detail below, that deformation-controlled melt segregation can, in addition to chemical effects, modify the thermal evolution of crystallising magmas.

In similar fashion, it is possible to compare the relative timescales of advection (At) versus diffusion (Dt) where the chemical diffusion coefficient $(D)$ and fluid velocity are known. Taking data for $\mathrm{H}_{2} \mathrm{O}$ diffusivity in silicate melts (Zhang and Ni 2010), we assess the relative importance of each for a given rate of shear strain. Setting At/Dt $=1$, the 

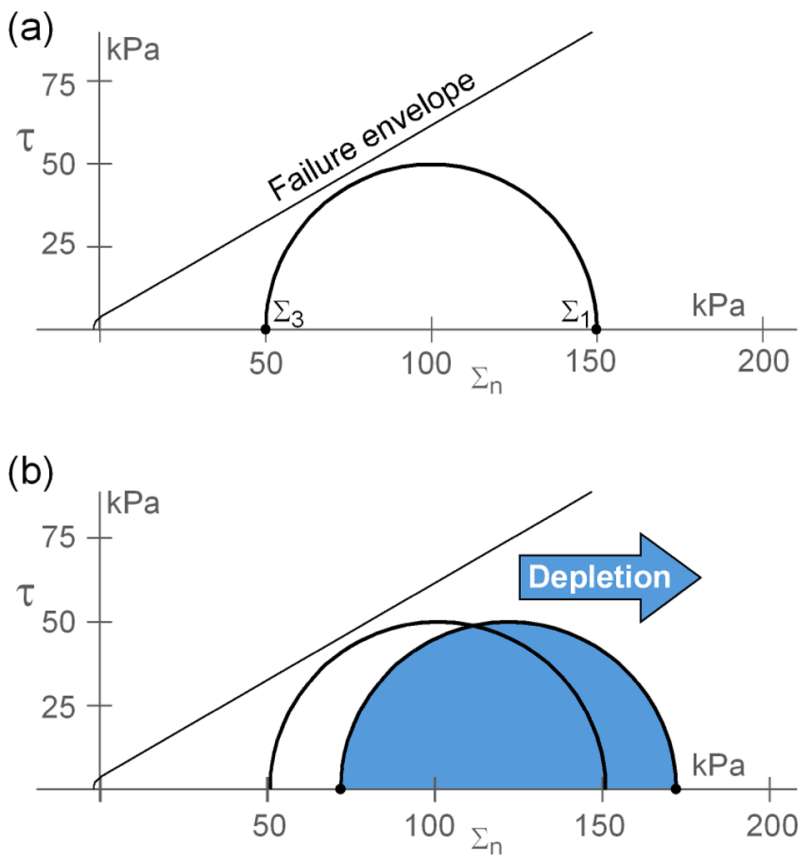

(c)

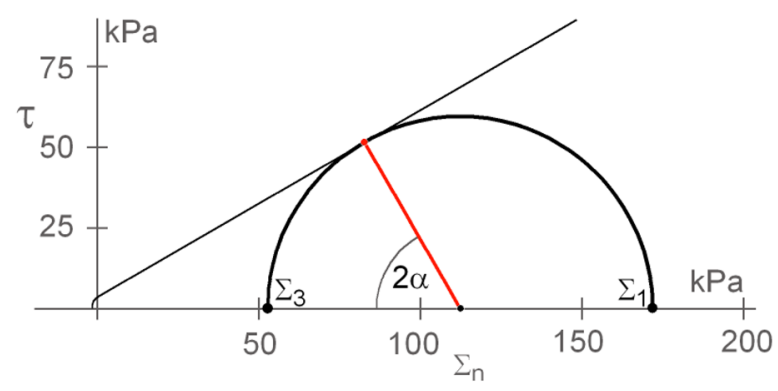

Fig. 5 Illustrative Mohr diagram and accompanying Coulomb-Griffith failure envelope, summarising the mechanical behaviour of a 10 -m thick dilating basalt layer comprising $80 \%$ solids using elastic constants for olivine (Table 4) and an interstitial melt viscosity of $10^{2} \mathrm{~Pa}$ s. a The situation at rest (static) with a differential skeleton stress of c. $100 \mathrm{kPa}$, a stress ratio $\Sigma_{1} / \Sigma_{3}=3$ and solid-melt density contrast $=300 \mathrm{~kg} \mathrm{~m}^{-3}$. b Dilation and accompanying drop in excess pore fluid pressure, calculated using Eq. 3 for a shear strain rate of $10^{-10} \mathrm{~s}^{-1}$. The corresponding increase in skeletal mean stress $(100$ $120 \mathrm{kPa}$ ) moves the circle to the right (shaded), away from the failure envelope. c Induced failure of the depleted mush caused by reducing the minimum confining stress by approximately $1 / 4$. The stress ratio at failure is 3.25 , with shear and normal stress at 52 and $83 \mathrm{kPa}$, respectively. The predicted angle of failure (where $2 \alpha=60^{\circ}$ ) relative to $\Sigma_{1}$ is $30^{\circ}$

characteristic time for the process is $t_{\mathrm{c}}=D / q^{2}$ where $t_{\mathrm{c}}$ is the time for advection and diffusion to equal each other (Lerman 1979). Table 3 summarises the order-of-magnitude influence of increasing deformation rate with respect to a fixed rate of chemical diffusion for $\mathrm{H}_{2} \mathrm{O}$ in basaltic and rhyolitic melts. At plate tectonic strain rates (not shown), melt flow rates

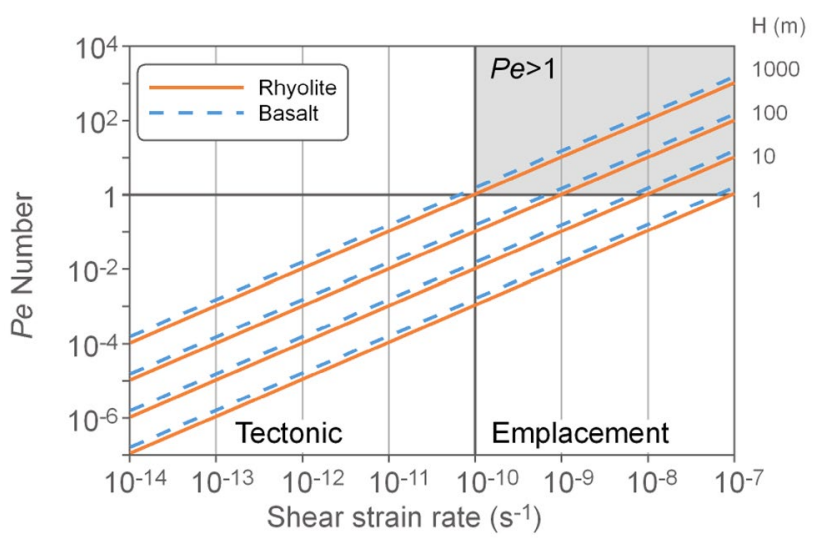

Fig. 6 Thermal Péclet number $(\mathrm{Pe})$ as a function of shear strain rate for rhyolite (solid line) and basalt melts (dashed line) with thermal diffusivities of $3.5 \times 10^{-7} \mathrm{~m}^{2} \mathrm{~s}^{-1}$ and $5 \times 10^{-7} \mathrm{~m}^{2} \mathrm{~s}^{-1}$, respectively (Hofmeister et al. 2009). At tectonic rates, velocities are significantly lower than the rate of thermal diffusion, implying that the magma will have crystallised completely before significant movement between melt and solid has occurred. The switch between diffusion and advection-controlled transport is governed (all else being equal) by the layer thickness under tectonic loading. Heat transport is dominated by flow of melt $(\mathrm{Pe}>1)$ for layer heights inside the shaded area

Table 3 Sensitivity analysis comparing the equivalent time for $\mathrm{H}_{2} \mathrm{O}$ (bulk volatile) diffusion and advection rates in basalt and rhyolite melts to equal each other in a $10 \mathrm{~m}$-thick deforming mush

Shear strain rate Equivalent transport time

\begin{tabular}{lll}
\hline & Basalt & Rhyolite \\
& $D_{\mathrm{H}_{2} \mathrm{O}}=5.8 \times 10^{-11} \mathrm{~m}^{2} \mathrm{~s}^{-1}$ & $D_{\mathrm{H}_{2} \mathrm{O}}=6.6 \times 10^{-12} \mathrm{~m}^{2} \mathrm{~s}^{-1}$ \\
$10^{-12} \mathrm{~s}^{-1}$ & $7 \times 10^{4}$ (year) & $8 \times 10^{3}$ (year) \\
$10^{-10} \mathrm{~s}^{-1}$ & 7.3 (year) & 0.8 (year) \\
$10^{-7} \mathrm{~s}^{-1}$ & $232(\mathrm{~s})$ & $26(\mathrm{~s})$ \\
\hline
\end{tabular}

are too slow to outpace chemical diffusivity. However, for shear strain rates $>10^{-12} \mathrm{~s}^{-1}$, advection caused by dilatancy dominates the transport process.

\section{Discussion}

We focus now more broadly on three lengthscales where shear-induced dilation may play a hitherto unrecognised role in imparting compositional diversity in igneous rocks. We begin with local fractionation and diffusive effects where chemical interchange between growing crystals at the melt interface operate on scales from microns to $\mathrm{mm}$. Following on, we look at compositional and mechanical effects on a metre to decimetre scale, taking as an example changes in a dense crystallising layer that may act to disrupt the normal, down-temperature sequence of fractional crystallisation. 
Finally, and more speculatively, in the context of crustal mush columns, we consider how the granular dilatant effect could be a precursor to larger scale mechanical failure of the mush pile, culminating in the transport of compositionally distinct melt out of the deforming region, through dykes or fractures.

\section{Microscale}

\section{Compositional effects in the system Ab-An}

We start by exploring the modifying effect of dilatancy using as an example the familiar plagioclase (Ab-An) binary system. The idea is that during a dilation event, $\mathrm{H}_{2} \mathrm{O}$-undersaturated melt will be siphoned into the interstices between plagioclase crystals. This newly introduced melt will shift the plagioclase equilibrium to favour growth of more calcic feldspar, producing an effect similar to that of increased $T$. Since the $\mathrm{H}_{2} \mathrm{O}$-undersaturated melt will be both hotter and less hydrous than the original melt in contact with the plagioclase crystals (Mead 1925; Clemens and Petford 1999; Clemens and Watkins 2001), the crystals would probably be partially resorbed and would certainly become reverse-zoned before returning to a normal zoning pattern.

Figure 7 shows the two-component plagioclase feldspar phase diagram at $1 \mathrm{~atm}$ (Bowen 1928). To see how the suction effect could work, assume that composition $\mathrm{X}$ has cooled along a familiar trajectory such that liquid and solid have remained in equilibrium on cooling to reach point $P$. Also note that implicit in the phase diagram is a mechanical element, analogous to the rheological divisions comprising solidification fronts. The shear-dilatant sensitive region begins where the two-phase mixture is equal to c. $80 \%$ solids, 20\% liquid and above, in accordance with the Lever Rule. The dilatant region (red stipple) is shown extending beyond a single isothermal tie line, drawn parallel with and up to the solidus curve. This region corresponds to the Mohr diagram analysis in Fig. 5 for a deforming mush layer, thus making the link between the mechanics during shear and the phase petrology of binary systems.

The labels in Fig. 7 show the potential effect of intrusion of hotter melt with less evolved composition, drawn upwards into the dilating crustal mush. On the grain scale, this is clearly a complex process that will involve mixing between the existing liquid in the framework and fresh melt. However, as shown diagrammatically, the net result will be an up-temperature shift with the addition of more, An-rich melt. Thus, at temperature $T_{2}$, the composition of the solid phase $\left(\mathrm{S}_{2}\right)$ is $\mathrm{An}_{58}$. An influx of hotter melt at $T_{3}\left(1350^{\circ} \mathrm{C}\right)$ will push the system to new equilibrium composition of $\mathrm{S}_{3}$ $\left(\mathrm{An}_{66}\right)$. Assuming instantaneous re-equilibration, this will cause reverse zonation. Depending on the local temperature gradient and duration of flow, resorption of crystals is also

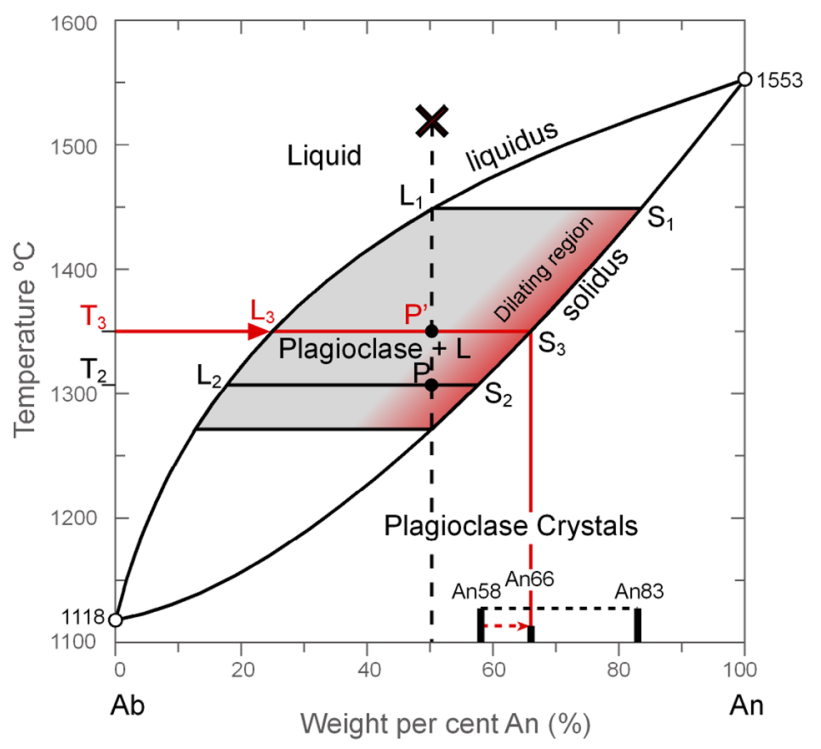

Fig. 7 An illustration of the effect of dilatancy on the composition of plagioclase. Staring with a normal fractionation (down temperature) trend at point $X\left(S_{1}, A n_{83}\right)$, the mixture has cooled to point $P\left(L_{2}\right.$ with An\% at $\mathrm{S}_{2}$ ). Shear deformation draws hotter melt into the dilating mush (red stipple) at temperature $T_{3}$. Plagioclase crystals (composition $\mathrm{S}_{2}=\mathrm{An}_{58}$ ) react with the auto-intruding An-rich liquid and shift to composition $\mathrm{S}_{3}$, with a new bulk composition $\mathrm{P}^{\prime}$. The zoning profile then reads $\mathrm{An}_{83}-\mathrm{An}_{58}$ (normal), $\mathrm{An}_{58}-\mathrm{An}_{66}$ (reversed). By extension, up-temperature transitions more generally could produce multiple reversed zoning patterns, scalloped discontinuities and resorption, commonly but mistakenly ascribed to the influx of external (foreign) melts

possible (Donaldson and Henderson 1988). Thus, oscillatory zoning patterns could be recorded in plagioclase crystals that formed without the involvement of any truly foreign magmas or changes in pressure. In such instances, plagioclase zoning could be misinterpreted as evidence of magma mixing or rapid magma ascent.

Figure 7 shows only the simplest example of how dilation of the mush, coupled with fluctuations in melt pressure, could disrupt the crystallisation sequence and impart compositional (and thermal) disequilibrium at a local scale. Similar effects should occur in dilating olivine $(\mathrm{Fo}-\mathrm{Fa})$ mushes. With the inclusion of more components, a relevant example being the system $\mathrm{Di}-\mathrm{Ab}-\mathrm{An}$, where the addition of diopside lowers the liquidus and solidus temperature of plagioclase, small changes in temperature (of a few $10 \mathrm{~s}$ of degrees $\mathrm{C}$ ) will result in large compositional shifts for liquids on the cotectic. It is thus easy to see how shearing and deformation of the mush could stall or even reverse temporarily, down-temperature fractional crystallisation trends. Following Emmons (1940), oscillatory zoning in minerals has the potential to record a structural history as well as a chemical one. 


\section{Mesoscale}

\section{Modification to solidification fronts}

Textbook behaviour for the cooling and crystallisation of plutonic rocks describes the familiar, down-temperature sequence of fractionation leading to compositional diversity. However, deformation and subsequent mush dilatancy has the potential to disrupt this normal sequence of events. We explain how below.

Figure 8 is a summary from McBirney (1984), complied from different sources including direct observation from lava lakes, that shows the relationships between temperature, composition and crystallinity in magma cooling from above. The vertical scale shows depth below the solidus. The region most sensitive to shear-induced dilation is that part of the layer in the range c. $0.7>\phi>0.9$. During the deformation events that we are discussing, a small amount of cooler, more hydrous melt, from near the roof zone might be drawn downward into the dilating mush. However, it is more likely that the bulk of the melt drawn in would be from the much larger reservoir of hotter, more liquid magma beneath. This

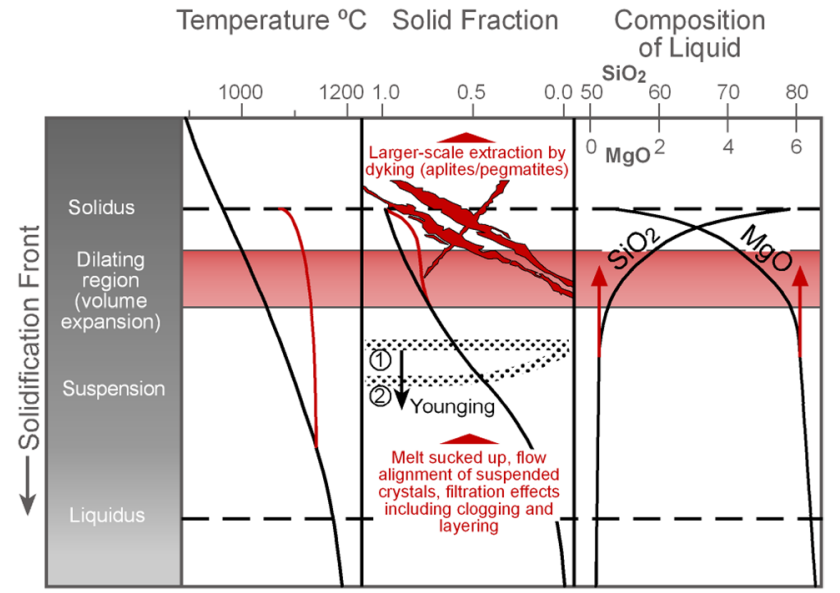

Fig. 8 Schematic vertical section through a generic solidification front (McBirney 1984; Marsh 2002) showing changes in temperature, crystal fraction and composition as a function of depth (black line), modified to include mechanical and compositional instabilities due to deformation. The following sequence of events are presented for consideration. (1) Shear-enhanced dilation sucks up hotter melt (red lines) from below (auto-intrusion) into the more congested (70-80\% solid) parts of the mush, resulting in elevated temperatures and compositional changes (red arrows). (2) 'clogging' and permeability reductions form layers in the suspension zone, the latter preserved sequentially (1-2, arrowed) as the capture front moves downwards. (3) Post-failure bifurcation and shear bands in the congested mush lead to accumulation of pools of evolved melt available to intrude locally/externally as late-stage fractures/dykes. Note the symmetry of the process such that a lower buoyancy mush collecting at the floor of a chamber will draw melt downwards into the dilating layer from above, with similar anticipated results is because both the porosity and permeability of the solidification front increase downward (Marsh 2002).

As shown in Fig. 7 for the system Ab-An, the effect of drawing in hotter melt would be to destabilise crystals next to the pores filled with newly introduced melt. In mafic systems, the residual liquid fraction at a crystal contents $>70 \%$ is enriched in $\mathrm{Fe}$ through crystallisation of $\mathrm{Mg}$-rich olivine and/or orthopyroxene. Thus, dilation will cause mixing with Mg-enriched liquids drawn from below. As with silicic systems, the net effect would be to cause partial dissolution of crystals and in mafic magmas, precipitation of more magnesian olivine and pyroxene.

In the example given (Fig. 8), the magma is cooling from above. The timescale of the advancing solidification front is thus relevant to the ability of the magma to differentiate chemically. Assuming simple monotonic cooling of a solidifying boundary layer (crust) moving downwards, the depth of the layer will increase with the square root of time according to $y_{1}=2 \lambda_{1} \sqrt{\kappa t}$ (Turcotte and Schubert 2002, p. 163). While the model is complicated by the fact that the dilatant effect will bring in heat from below (see Fig. 6), that could act to stall the solidification process, we calculate it would take approximately 4.4 years for the solidification front to cool $10 \mathrm{~m}$. Given a shear strain rate of $10^{-7} \mathrm{~s}^{-1}$, melt segregation during dilation could transport liquid (and chemical components) over this same distance in c. 80 days. McBirney (1984) noted that some kinds of layering in igneous rocks, such as economically important chromite bands, appear to require high fluxes of chemically undepleted liquid to flow though the zone of crystallisation. Shear-aided dilatancy might help achieve the required local flow rates by drawing fresh melt into the solidification front.

\section{Potential structures and textures resulting from dilatancy}

It remains an open question as to the range of structures and textures that might be preserved during dilatancy of a congested magma mush. Possible examples from the field, and those produced experimentally, are shown in Fig. 9. The felsic segregations in the Gaos Suite gabbros (Fig. 9a) are comprised of plagioclase feldspar with minor quartz and hornblende. Clearly, this composition is late-stage in origin, and its intergranular distribution, apparently pseudomorphing the melt phase, is consistent with textures we regard as indicative of pre-failure Reynolds dilatancy. Similar geometries are seen in deformation experiments performed on aggregates of olivine and $\mathrm{FeS}$, where evidence for granular dilatancy is reflected in pooling of liquid metal sulphide into pockets and interstices between the matrix grains. At this stage we do not propose these observations are conclusive, and acknowledge that other explanations may be just as good. Indeed, Renner et al. (2000) argued that direct measurement of volumetric strain is needed to confirm granular 
(a)

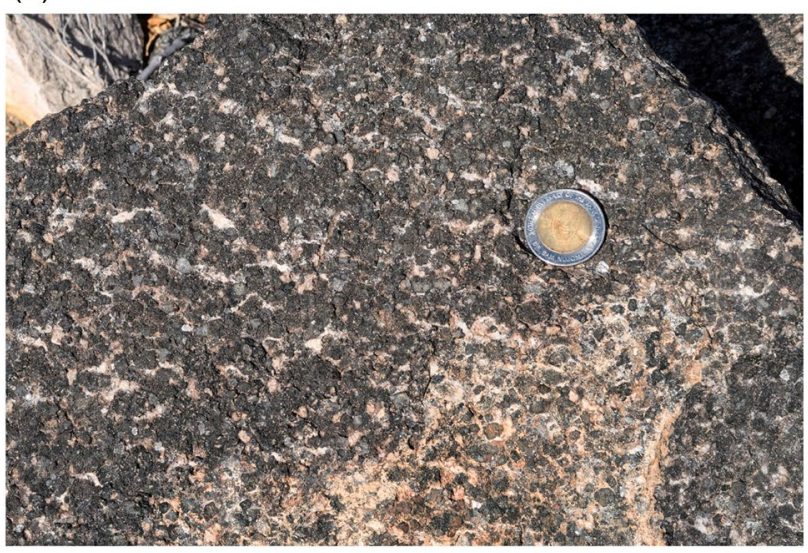

(b)

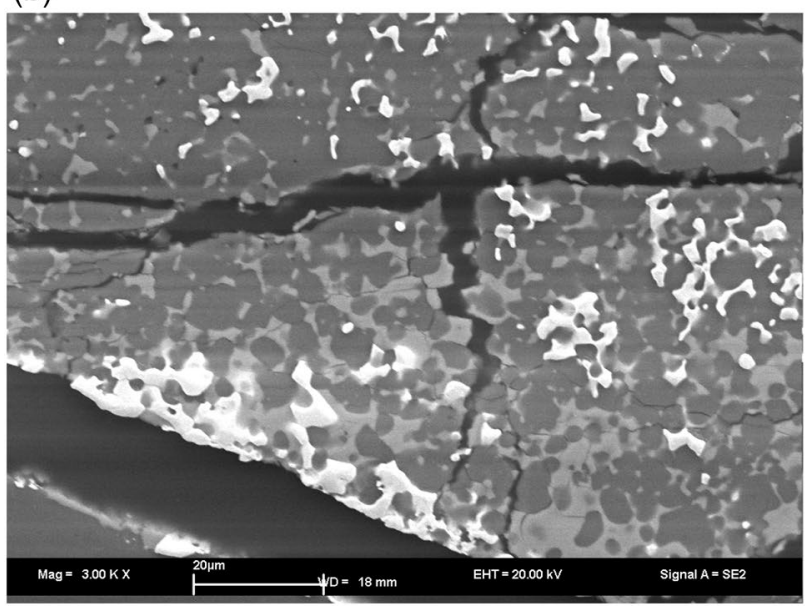

Fig. 9 a Cumulate gabbroic and gabbroic diorite from the Oamikaub Ring Complex, Goas Suite, Namibia. Felsic segregations (pink) have formed an intergranular network of the kind envisaged during Reynolds dilatancy where, pre-failure, an evolved melt phase of feldspar and quartz has segregated out locally into pockets to form interconnected strings. b Backscatter SEM image of synthetic olivine $\left(\mathrm{Fo}_{90}\right)$ plus ca. 25 vol.\% FeS deformed during simple shear, strain rate ca. $10^{-4} \mathrm{~s}^{-1}, T=1250{ }^{\circ} \mathrm{C}$. The distribution of quenched FeS melt fraction (light grey) between darker grey olivine shows close similarity to interstitial liquid distributions in the Goas gabbros and dilating alloys at similar solid fractions (e.g. Cai et al. 2015 and supplementary materials, Figs. 3-6)

dilatancy in laboratory experiments on partially molten rocks. However, the geometrical similarity between meltphase structures observed in the field and from experiments (Fig. 9), with those seen in shear-dilated high-temperature alloys, is noteworthy.

Regarding microstructural evidence for dilatancy, van der Molen and Peterson (1979) describe melt redistribution into reservoirs oriented sub-parallel to the maximum compressive stress, consistent with locally dilatant, brittle processes. Contact forces between grains in the dilating skeleton will increase as the coordination number drops with loading
(Fig. 2a). The resulting stresses at grain contacts may be high enough to promote intergranular fracturing. As the contact stresses increase with decreasing radius of curvature (Johnson 1985), smaller grains are more susceptible to breaking, leading in time to an increase in grain size range in the assemblage.

It is also the case in theory (Appendix Eqs. 5 and 6), that as the granular material is loaded deviatorically, directional effects become pronounced. This takes place because, in the major principal stress direction, contacts are made, while in the minor principal stress direction, contacts are deleted. In time the fabric of the material becomes stretched (the evolution of the fabric tensor tends to follow the changes of the stress tensor) and anisotropy is induced. One manifestation of this could be foliations or lineations with a preferred orientation.

Finally, in the more melt-dominated regions of solidification fronts, upwelling and trapping of smaller, suspended particles might cause permeability reductions by blocking and chocking, analogous to filtration effects (caking), common in industrial processes that involve two-phase flow (Wakeman and Tarleton 2005). Structures formed in this way, along with the rotation and preferred alignment of larger suspended crystals frozen in during cooling, could account for some 'sedimentary-type' features preserved in plutonic rocks (e.g. Barriere 1981; Paterson et al. 2019). The mechanical consequence of permeability (physical and geometric) fluctuations more generally, linked to fluid flow in solidification fronts, is discussed later.

\section{Post-failure rupture layers and fracturing}

It is reasonable to assume that if shear is maintained for long enough, a dilating mush will rupture (e.g. Fig. 5c). This is referred to in the granular mechanics literature as a bifurcation (Rudnicki and Rice 1975; Sheikh-Ansari and Aghaie-Khafri 2018) the technical meaning of which is that the governing equations change from elliptic (pre-failure) to either hyperbolic or parabolic. After the bifurcation point is reached, our model breaks down and can say nothing quantitatively about the continued evolution of the system as it deforms. However, we can look for field evidence for bifurcation where pre-failure deformation may have provided a precursor to subsequent rupture. For example, dilatant shear bands are likely to form during deformation of congested magmas (see Schall and Hecke 2009). Significantly, similar structures, along with micro-segregation and fracturing (hot tears), have been observed in experiments and numerical simulations of semi-solid alloy mushes (Gourlay and Dhale 2007; Su et al. 2019). Candidate examples with geometrical similarities occur in dolerites comprising the Basement Sill, Antarctica (Marsh 2004). Here, cm-scale plagioclase segregations within a course granular Opx matrix, form 
closely spaced sub-parallel layers. Figure 10a shows an individual layer in detail that shares features with sheared granular alloys including a characteristic width defined by $<20$ particle diameters (Meylan et al. 2010). Previously the origin of these layers has been ascribed to bulk flow and shear of congested magma (Petford and Mirhadizadeh 2017). However, it is possible these (along with other more silicic segregations), formed during shear-aided dilation of

(a)

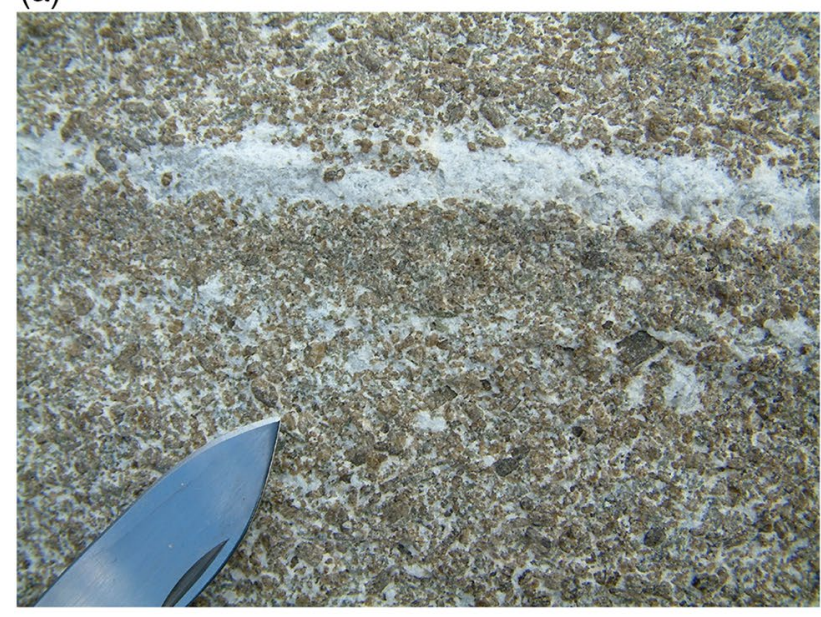

(b)

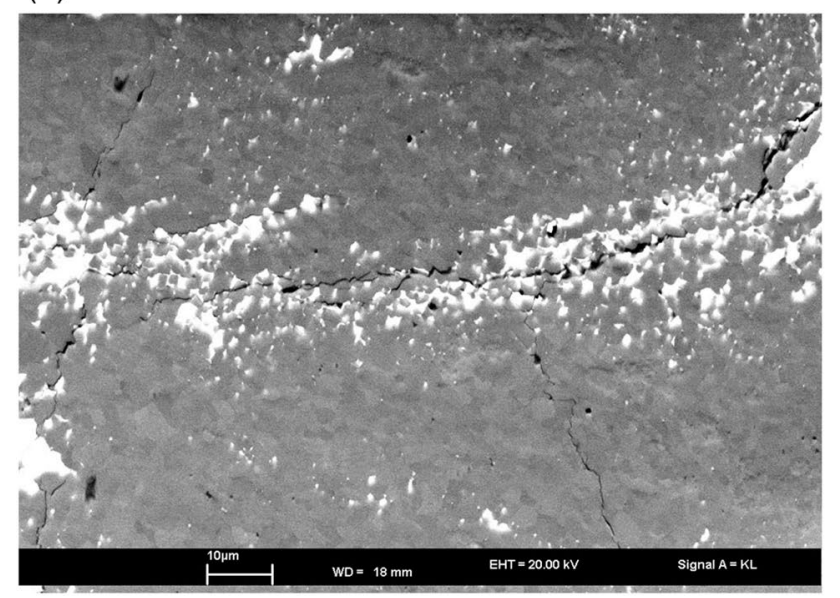

Fig. 10 Field and experimental examples of potential post-failure structures following Reynolds dilatancy in partially molten rock (see also Petford 2009). a Centimetre-scale plagioclase banding in an Opx-rich matrix emplaced as a granular magmatic slurry (Basement Sill, Antarctica, Marsh 2004). The structure width is c. 10 Opx grains wide. Although interpreted previously as the result of particle segregation during flow (Petford and Mirhadizadeh 2017), the geometrical similarity to melt-rich shear bands formed in deforming alloys (generally 10-16 grain diameters wide, Meylan et al. 2010), is consistent with in situ granular dilatancy. b BSE image of a deformation experiment (strain rate ca. $6 \times 10^{-4} \mathrm{~s}^{-1}, T \sim 1250{ }^{\circ} \mathrm{C}$ ). Segregations of $\mathrm{FeS}$ were sucked from the sample into polycrystalline alumina pistons to form alignments of connected melt pockets driven by reductions in pore fluid pressure associated with dilatancy (see Petford et al. 2007; Fonseca et al. 2013, and supplementary materials Figs. 7-9) the Sill magmas after emplacement. A supporting example of this is given by Geshi (2001) who describes the in situ segregation during shear of interstitial trachyte melt into an array of conjugate, en-echelon veins. Similar instabilities in solidifying, congested magma are commonplace (e.g. Brown and Rushmer 1997; Marsh 2002). The effects of melt-rich dilatant zones that focus and accumulate fluid at high solid fractions are two-fold. First, melt bands will stay hotter and more liquid for longer than interstitial melt in the enclosing matrix. Second, because they are rheologically weaker than their surroundings, they will act as foci for continued deformation (Stevenson 1989). This is seen to some extent in Fig. 10b where, during experimental deformation, a drop in pore fluid pressure associated with dilatancy has caused melt to be forced out of the specimen and into the surrounding medium. The additional pore space required to accommodate melt sucked into the matrix is achieved by further dilation.

At larger scales, post-failure pressure changes associated with dilatancy and rupture in granitic magmas might ultimately drive the segregation of residual melt into veins and dykes (e.g. Clemens et al. 1997; Clemens and Stevens 2016) to form late-stage aplites and pegmatites (e.g. Emmons 1940; Sisson and Bacon 1999; Waters and Lange 2017). In mafic systems, the outcome could be segregations of granophyre and evolved alkaline rocks, as proposed by Bowen (1920). In this way, discontinuous variations in composition at outcrop scale are traced back to initial deformation at the pore scale.

\section{Macroscale}

\section{Dilatancy in crustal melt columns: turbo-charging the segregation process?}

In considering the origins of discontinuous variation, Bowen (1920) argued that bimodal compositions in igneous rocks were not caused by gravitational processes, but where instead a compositional signature of magma differentiation by deformation. In this context, long-standing models of large, mostly liquid, crustal-scale magma chambers (Jaupart and Tait 1995) are being replaced by the idea of vertically extensive columns of magma mush through which buoyant melt can percolate (Cashman et al. 2017; Jackson et al. 2018; Sparks et al. 2019). End-member compaction theory provides an elegant solution in purely viscous systems (Jackson et al. 2018), but segregating chemically evolved liquids from putative columns fast enough to account for observed eruption volumes (c. $>10 \mathrm{~km}^{3}$ ) of silicic magma remains problematic (e.g. Holness 2018; Bachmann and Huber 2018). One reason for this could be the self-limiting notion of rheological 'lock-up' in crystal mushes when the solid fraction exceeds a critical threshold (e.g. Vigneresse et al. 1996; 
Bachmann and Huber 2018; Floess et al. 2019). Attempts to explain crystal mush reactivation in silicic systems via an interplay of melting and gas addition (Huber et al. 2011), strike us as unnecessarily complex. Although in-situ deformation and the local stress state are recognised as important but poorly constrained properties in three-phase flow, these models still promote a fixed shear viscosity for the deforming matrix, along with buoyancy-driven melt flow (Huber and Parmigiani 2018), in contrast to the contact mechanics one presented here. In our model, deformation pushes both the temperature and permeability of crystal-rich systems from the background state (see Fig. 9), away from thermal equilibrium. Indeed, high crystal contents $(0.7>\phi>0.9)$ are a fundamental initial condition, without which dilatancy and the segregation of interstitial melt cannot occur. During deformation, there is no critical rheological threshold.

Given this, the following sequence of events is tentatively proposed to highlight the cascading role and evolving style of deformation as a way to extract viscous silicic melt quickly from a mush. As such, this work is in part an attempt to help connect thermal models of magma rejuvenation with the contact mechanics of mush systems as they deform. First, the nature of the required deformation. As shown here, background plate tectonic rates are insufficient for dilatancy to have much effect. A more local cause, integral to the magma generation processes, is required. Most models of crustal-scale magma reservoirs regard intrusion and thermal recharge by newly accreted magma bodies as central to their longevity (Cashman et al. 2017; Sparks et al. 2019). However, mechanical disruption is not explicitly accounted for (e.g. Jackson et al. 2018). For example, a $100 \mathrm{~m}$ thick sill emplaced into a pre-existing, $1 \mathrm{~km}$-high mush column in 1 year gives a shear strain rate of c. $10^{-9} \mathrm{~s}^{-1}$, sufficient to initiate dilatancy and extract melt from silicic mushes much faster than viscous compaction (Fig. 4). Multiple intrusions could create a near-continuous deformation field, allowing melt to segregate rapidly through a combination of granular (pre-failure) dilatancy into melt-rich layers, followed by hydraulic failure of the mush and draining upwards of the evolved, pooled melt via dykes. In support, Christopher et al. (2015) interpret geophysical and geochemical data on bursts of gas flux at the Soufrière Hills Volcano, Montserrat, as evidence for fluid-filled fractures propagating through at least $5 \mathrm{~km}$ thickness of mush. Should an eruption begin, shear strain rates during catastrophic venting of batholith-volume magmas may increase to $10^{-4}-10^{-3} \mathrm{~s}^{-1}$ (Gottsmann et al. 2009), further accelerating melt flow in the dilating magma. At even higher shear strain rates $\left(>10^{-3} \mathrm{~s}^{-1}\right)$, deformation caused by the eruption itself could become the agent of continued melt extraction, analogous to Reynolds dilatancy in agitated wet sand. Clearly, the above sequence is speculative and needs more consideration. However, volume expansion of a dilating, sub-volcanic mush would result in heave.
Surface uplift is a common precursor to volcanic eruptions (e.g. Amelung et al. 2000) and could provide a direct observational test of the dilatant model.

One last point relates to vertical variations in mush permeability, above and below the dilating region. This set-up was explored in detail by Koenders and Petford (2005) but is relevant to the situation here, especially if melt flow results in an abrupt decrease in permeability through choking or clogging as discussed earlier. The effect is likely to be scale invariant. Figure 11 shows the effect in non-dimensional form, where an increase in layer permeability shifts the pore pressure to the negative side. Reduced pressure in the melt phase may have the secondary effect of causing bubbles to form, making the fluid compressible. A corresponding, very substantial pressure gradient forms above the clogged layer, which will have mechanical implications for its integrity. Similar, near-impermeable clogging boundaries, have been identified in granitic plutons where mafic intrusions separate layers of crystal-rich deformable mush, with the potential to trap residual melt during deformation (Wiebe 1993). The greater the permeability contrast between and within layers, the more severe the effect. It appears that the skeletal matrix properties of deforming mushes play critical roles, yet to be fully resolved, in governing the discontinuous compositional variation in igneous rocks (Bowen 1920).

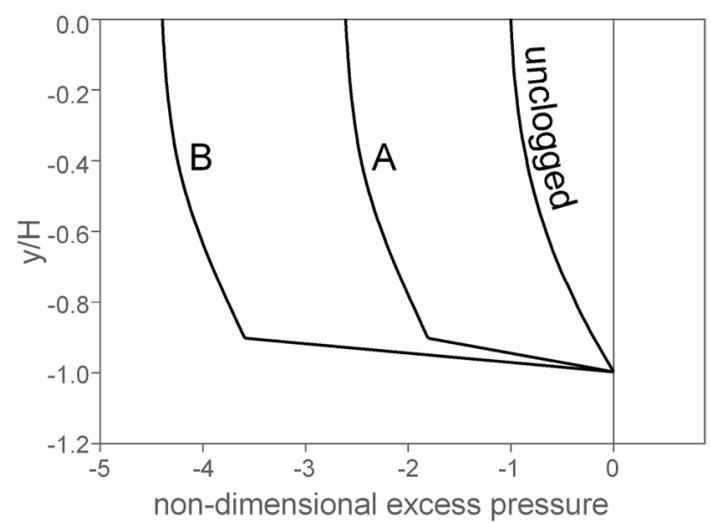

Fig. 11 Illustration of the non-dimensional excess pore pressure through a vertical mush layer where clogging (reduction in permeability) due to filtration effects has occurred. The clogged layer has an arbitrary thickness of $0.1 \mathrm{H}$. The unclogged system is shown for comparison. Two curves are shown: $A$ permeability ratio $=10 ; B$ permeability ratio $=20$. The effect of a reduction in layer permeability is to progressively reduce the (non-dimensional) pore pressure and cause a large pressure gradient across the clogged (low permeability) layer. A descriptive interpretation suggests that during deformation, bubbles may form in the melt phase due to reduction in pressure, with potential rupture of the low-permeability layer. Implications for the mechanical stability of the mush are discussed in the text 


\section{Summary}

Recent developments in high-definition mineral chemistry at the grain scale are shedding new light on the processes and rates of magma storage, differentiation and eruption. However, the complementary physics and fluid dynamics of melt extraction are still based primarily on viscous compaction theory. We regard this as problematic and possibly irrelevant in sub-volcanic settings where magma is being deformed by external shear. Our modification to Biot's governing theory, while exploiting a Darcian approximation for porous flow, emphasises the elastic response of a granular assemblage to deformation as a pre-requisite for fluid motion over and above buoyancy effects and, to a lesser extent, melt viscosity. Key parameters governing the dilatancy effect are the loading rate, physical permeability, mush strength, shear modulus and the contact mechanics of the assemblage. While acknowledging that information on some material parameters is scant, best estimates are provided. We present expressions for (1) the time to dilation, (2) the pressure change in the interstitial melt phase, and (3) associated melt flow rates as a function of shear strain rate. We show that where shear strain rates exceed the local tectonic background, pressureinduced melt flow can locally redistribute heat and mass through sparingly permeable, highly congested magma at velocities far in excess of either buoyancy forces or diffusion. Unlike static mushes, there is no 'lock-up' state above which the interstitial melt cannot percolate. Co-mingling of auto-intruding melt has the potential to interrupt (or locally reverse) fractionation trends. Microscale evidence (in plagioclase or olivine) would include overgrowth by new, more calcic feldspar or Mg-rich olivine to produce reverse zoning or resorption, mimicking some of the textural effects normally attributed to magma mixing. Particles (smaller crystals) trapped or deposited during melt flow may contribute to some sedimentary-like features observed in plutonic rocks.

At the mesoscale, the state of mean stress in the magmatic layer arising from buoyancy forces, modified for changes in pore fluid pressure during shear, provides estimates of shear strength and effective stress analogous to standard geotechnical assessments of rock and soil. Following on, indicative Mohr analysis shows that during dilation, the increase in effective skeletal stress could produce a situation similar to that in depleted hydrocarbon reservoirs. Continued post-failure instabilities (bifurcation) including hydraulic rupture of the mush, may act as sites of nucleation for dykes, including pegmatites and aplites, with the potential to drain and redistribute compositionally distinct melt fractions across the system. While the role of $\mathrm{H}_{2} \mathrm{O}$ and exsolved volatile phases will complicate the picture by making the melt phase compressible and modifying the viscosity, these effects can be added to the analysis at a later stage. Mush strength (both compressive and tensile), coordination numbers, the effect of particle geometry on distribution and magnitude of contact forces and elasto-viscous effects remain uncertain. Post-failure, the underlying mechanics controlling magmatic shear bands appear to be governed by dilation angles and internal friction. More experimental work is needed if we are to better constrain these variables for modelling purposes in partially molten systems. Since melt flow vectors during dilation are not constrained by gravity, at larger scales (e.g. in putative crustal-scale mush columns), drainage effects could potentially disrupt the perceived normal sequence of igneous differentiation. Rather than one primary mechanism responsible for extracting highly silicic melt from plutonic mushy zones, a series of deformation events, unfolding on a range of scales, might agree better with the volcanic record in terms of rates and erupted volumes.

Finally, with the addition of time-dependent effects (constitutive creep) in the granular matrix, the model may find new application in porous regions of the deep Earth and further afield, unknown in Bowen's time. Potential sites include mushy layers at the inner core and the cryospheres of icy planets.

Acknowledgements NP acknowledges Nico Walte and the EU Research Infrastructures Access Programme for conducting the deformation experiments. Bruce Marsh, George Bergantz and Alan Whittington are acknowledged for their insights into the granular and thermal behaviour of magmas that informed this work. NP and CK thank the Southbank Centre, London for services provided. Andrew Dean developed the online dilatancy calculator. We thank Paul Stroud for preparing the figures and two reviewers who helped improve the presentation of the manuscript.

Availability of data and materials Online resources (a web-based dilatancy calculator) is available at: http://www.computing.northampto n.ac.uk/ dilatancy/.

Open Access This article is licensed under a Creative Commons Attribution 4.0 International License, which permits use, sharing, adaptation, distribution and reproduction in any medium or format, as long as you give appropriate credit to the original author(s) and the source, provide a link to the Creative Commons licence, and indicate if changes were made. The images or other third party material in this article are included in the article's Creative Commons licence, unless indicated otherwise in a credit line to the material. If material is not included in the article's Creative Commons licence and your intended use is not permitted by statutory regulation or exceeds the permitted use, you will need to obtain permission directly from the copyright holder. To view a copy of this licence, visit http://creativecommons.org/licenses/by/4.0/.

\section{Appendix}

A sheared granular medium evolves from a near isotropic state to a highly anisotropic one. The fabric tensor, that is the quadratic fit of the mean angular contact distribution, follows the skeletal stress tensor development. The latter 
evolves from an initial state in which the principal stress directions are aligned with coordinate axes (chosen to align with the direction of gravity and normal to it) to a stress ellipse that makes an angle of nearly $\pi / 4$ with the gravity direction. A simulation of the shearing of a granular material is reported in Thornton and Sun (1993). The results of the simulations show clearly that the stress development exhibits an initial state in which the stress ratio jumps up to a certain level and then remains more or less constant while the shear increases. The volume strain, meanwhile, quickly reaches a constant rate while the axial strain is increased. The fabric tensor tends to follow the direction of the stress tensor; the ratio of major to minor axis is in the region of 2 once the initial jump has taken place. The ratio of the major to minor principal stress is in the order of 5-6 for lightly loaded materials.

In the coordinate frame that is aligned with the major/ minor principal stresses the incremental stress-strain relation in two dimensions has the form:

$\left(\begin{array}{c}\dot{\Sigma}_{11} \\ \dot{\Sigma}_{12} \\ \dot{\Sigma}_{22}\end{array}\right)=\left(\begin{array}{ccc}A_{1111} & 0 & A_{1122} \\ 0 & G & 0 \\ A_{2211} & 0 & A_{2222}\end{array}\right)\left(\begin{array}{l}\dot{e}_{11} \\ \dot{e}_{12} \\ \dot{e}_{22}\end{array}\right)$,

(the stresses in the third direction do not play a significant role, as the whole deformation is two-dimensional) Now, in the end state the determinant $A_{1111} A_{2222}-A_{1122} A_{2211} \rightarrow 0$ and the shear modulus $G$ is very much reduced from its initial value. The ratio $\delta=A_{2211} / A_{2222}$ is the dilatancy ratio in a biaxial cell test and for dense materials typically in the order of $2-3$.

In order to obtain the stiffness tensor for increments a rotation is carried out, see the Appendix $\mathrm{C}$ of Koenders and Petford (2005). In the rotated frame, at an angle of $\pi / 4$ the following moduli and combination of moduli are found:

$$
\begin{aligned}
& a_{1212}= \frac{1}{4}\left(A_{1111}-A_{1122}-A_{2211}+A_{2222}\right) ; a_{2211} \\
&=-\frac{1}{4}\left(A_{1111}-A_{1122}+A_{2211}-A_{2222}\right), \\
& a_{1212} a_{2222}-a_{2212} a_{1222} \\
&=\frac{1}{4} G\left(A_{1111}-A_{1122}-A_{2211}+A_{2222}\right) \\
& \quad+\frac{1}{4}\left(A_{1111} A_{2222}-A_{1122} A_{2211}\right),
\end{aligned}
$$

The friction ratio $A_{1122} / A_{2222}=\Sigma_{1} / \Sigma_{3}$, where $\Sigma_{1}$ and $\Sigma_{3}$ are the major and minor principal (skeleton) stresses in the end state. Using the constitutive ideas put forward in the limiting state, the determinant vanishes and substituting the dilatancy ratio, the above moduli (combinations) turn out to be: $a_{1212}=\frac{1}{4} A_{2222}\left(\frac{\Sigma_{1}}{\Sigma_{3}}-1\right)(\delta-1) ; a_{2211}=\frac{1}{4} A_{2222}\left(\frac{\Sigma_{1}}{\Sigma_{3}}+1\right)(1-\delta)$

$a_{1212} a_{2222}-a_{2212} a_{1222}=\frac{1}{4} G A_{2222}\left(\frac{\Sigma_{1}}{\Sigma_{3}}-1\right)(\delta-1)$,

$a_{2112}=\frac{1}{4} A_{2222}\left(\frac{\Sigma_{1}}{\Sigma_{3}}(\delta-1)-\delta+1\right)$.

In these limits the following parameters may be summarised:

$\theta=G ; R=\frac{\Sigma_{1} / \Sigma_{3}+1}{\left(1-\Sigma_{1} / \Sigma_{3}\right)(G n \beta+1)} ;$

$\dot{c}_{0}=-\frac{1}{4} A_{2222}\left(\Sigma_{1} / \Sigma_{3}(\delta+1)-\delta-1\right) \frac{\partial \dot{v}}{\partial y}$,

where $\dot{v}$ is the vertical displacement velocity. Alternatively, expressing it directly in the applied horizontal shear:

$\dot{c}_{0}=\frac{1}{8} A_{2222}\left(\Sigma_{1} / \Sigma_{3}(\delta-1)-\delta+1\right) \frac{\partial \dot{u}}{\partial y}$,

with the all-important end-state coefficient:

$\frac{R \dot{c}_{0}}{\theta}=\frac{A_{2222}\left(\Sigma_{1} / \Sigma_{3}+1\right)(1-\delta)}{8 G(G n \beta+1)} \frac{\partial \dot{u}}{\partial y}$.

The essential part of this is the ratio $A_{2222} / G$ in the endstate. To get an impression of this quantity the idea is pursued that it can be derived from a contact distribution and a contact stiffness. The stress in a granular medium is generated from the expression:

$\Sigma_{i j}=\frac{1}{2 \bar{v}} \overline{\substack{\text { particle } \\ \text { contacts }}} F_{i} c_{j}$,

where $\bar{v}$ is the mean volume per particle; $\mathbf{F}$ the contact force vector and $\mathbf{c}$ the branch vector (that is, the vector connecting the centres of two neighbouring particles). The over bar implies an average over all particles in the assembly.

To obtain the moduli for incremental motion a contact stiffness is introduced. This quantity gives the relation between a contact displacement increment and the accompanying contact force increment. The contact displacement increment may be described by a (local) strain; as an average is taken in the first instance the mean strain increment $\dot{\mathbf{e}}$ is used. The contact stiffness is a tensor $\boldsymbol{\Lambda}$ and the contact relation takes the form:

$\dot{F}_{i}=\Lambda_{i p} \dot{e}_{p q} c_{q}$.

The contact stiffness tensor is anisotropic with respect to the contact direction $\mathbf{n}$; for spherical particles $\mathbf{c}=\mathbf{n} \bar{c}$, 
where $\bar{c}$ is the average distance between two contacting particles. Various approximations are made here. To begin with, there is good evidence that the particles are anything but spherical. Then there is the fact that the particles are hardly mono-sized. Also, the nature of the contacts varies tremendously in reality: a sharp edge may contact with a smooth neighbour or two smooth neighbours may participate, a rough one may contact a smooth one, etc. All these variations affect the outcome of the analysis, however, little is known about the impact of these phenomena and it must be kept in mind that a ratio of assembly averages are sought. Therefore, $\boldsymbol{\Lambda}$ is related to two material constants, one for the normal response and one to the tangential one:

$\Lambda_{p q}=\lambda^{(n)} n_{p} n_{q}+\lambda^{(t)}\left(\delta_{p q}-n_{p} n_{q}\right)$.

To then obtain an expression for the sum over all particles the latter is replaced by an integral over a contact distribution. The latter is diagonal with respect to the coordinate axes:

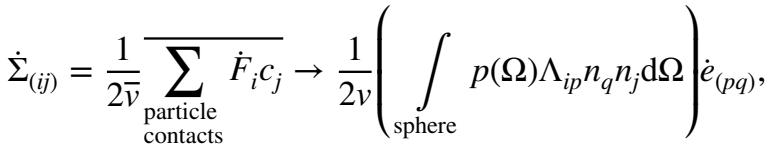

with $p(\Omega)=p_{\ell m} n_{\ell} n_{m}$, with $p_{\ell m}=0$ if $\ell \neq m$. Symmetrising brackets were used, because the stress and strain are symmetric.

The ratio $A_{2222} / G$ is then:

$\frac{A_{2222}}{G}=2 \frac{3 \lambda^{(n)}\left(p_{11}+5 p_{22}+p_{33}\right)+2 \lambda^{(t)}\left(2 p_{11}+3 p_{22}+2 p_{33}\right)}{2 \lambda^{(n)}\left(3 p_{11}+3 p_{22}+p_{33}\right)+\lambda^{(t)}\left(8 p_{11}+8 p_{22}+5 p_{33}\right)}$.

Typically, $\lambda^{(n)} \approx 2 \lambda^{(t)}$ and the intermediate fabric contribution is $p_{33} \approx \frac{1}{2}\left(p_{11}+p_{22}\right)$. If these estimates are used the ratio ends up as $\frac{4}{49} \frac{15 p_{11} / p_{22}+41}{p_{11} / p_{22}+1}$, which is roughly 1.22 for large anisotropies.

On this basis the two moduli are then in the same order of magnitude.

The expression:

$\frac{R \dot{c}_{0}}{\theta}=\frac{A_{2222}\left(\Sigma_{1} / \Sigma_{3}+1\right)(1-\delta)}{8 G(G n \beta+1)} \frac{\partial \dot{u}}{\partial y}$,

can now be used to estimate the flow rate into the medium. Simple differentiation yields for the rate at the bottom:

$q=\frac{A_{2222}\left(\Sigma_{1} / \Sigma_{3}+1\right)(1-\delta)}{8 G(G n \beta+1)} H \frac{\partial \dot{u}}{\partial y}$.

When the dilatancy ratio $\delta<1$ the fluid is squeezed out, but when $\delta>1$ it is sucked in-exactly as expected. The order of magnitude of the flow is $(1-\delta) H \partial \dot{u} / \partial y$.
The whole analysis then only requires an estimate of the stress ratio and a ratio of the moduli and the compressibility of the fluid. The actual value of the permeability is not required. The key parameters are the thickness of the layer and the applied shear.

One aspect that has been overlooked so far is evolution of the moduli due to the shearing. The question is really whether the applied shear is strong enough to push the medium into the dilatant régime. In order to ascertain that the magnitude of the moduli is estimated and then-evaluating from the initial state-calculate how long it takes for the applied shear to induce the mean existing pre-stress. If this happens, then one can be confident that the applied shear will be able to push the medium to a sufficiently high stress ratio for the assumptions about the moduli in the end state to be reasonable.

Next, in an order of magnitude calculation the contact force has an average magnitude $|F|$ and will be directed more or less away from the particle. The branch vector will have a magnitude of the average particle diameter $d$. Thus the order of magnitude of the stress is related to the order of magnitude of the strain as:

$|\Sigma|=\frac{1}{2 \bar{v}}|F| d \overline{\sum_{\text {contacts }} n_{i} n_{j}}$.

The sum over the contacts is of the order of magnitude of $\frac{Z}{2 \pi} \frac{4 \pi}{3}=\frac{2}{3} Z$, where $Z$ is the average number of contacts per particle. Furthermore, $\bar{v}=\frac{1}{\phi} \frac{4 \pi}{3}\left(\frac{d}{2}\right)^{3}$, with $\phi$ the crystal content (solidosity). The overall stress follows from either the depth of the problem $\rho g Y$, or the density contrast $\frac{1}{2} \Delta \rho g H$ (these are again orders of magnitude; the various stress components may well vary). Now the average contact force magnitude is

$|F|=\frac{2 \bar{v}}{d} \frac{3}{2 Z}|\Sigma|=\frac{8 \pi}{3 d} \frac{d^{3}}{8} \frac{3}{2 \phi Z}|\Sigma|=\frac{\pi d^{2}}{2 \phi Z}|\Sigma|$.

Using the Hertz formula for spheres the contact stiffness is:

$k_{c}=\frac{3}{2} \frac{F_{\perp}^{1 / 3}}{Q^{2 / 3}}\left[\left(\frac{1}{R}+\frac{1}{R^{\prime}}\right)\right]^{-1 / 3}$,

with:

$Q=\frac{3}{4}\left(\frac{1-v^{2}}{E}+\frac{1-v^{\prime 2}}{E^{\prime}}\right)$,

and $v, v^{\prime}$ the Poisson ratios of the participating particles and $E, E^{\prime}$ the Young's moduli of the minerals (Table 4). For the particle radii $R, R^{\prime}$ use $d / 2$. The assembly stiffness is then of the order of magnitude of: 
Table 4 Range of elastic properties for plagioclase, olivine $\left(\mathrm{Fo}_{90}\right)$, pyroxene (augite) and quartz used in the text

\begin{tabular}{|c|c|c|c|c|c|c|c|c|c|c|c|c|c|}
\hline \multicolumn{5}{|c|}{ Plagioclase $^{\mathrm{a}}$} & \multicolumn{3}{|c|}{ Olivine $^{\mathrm{b}}$} & \multicolumn{3}{|c|}{ Pyroxene $^{c}$} & \multicolumn{3}{|l|}{ Quartz $^{\mathrm{d}}$} \\
\hline$T(\mathrm{~K})$ & An\% & $E(\mathrm{GPa})$ & $v$ & $G_{\mathrm{VHR}}(\mathrm{GPa})$ & $T(\mathrm{~K})$ & $G(\mathrm{GPa})$ & $E(\mathrm{GPa})$ & $E(\mathrm{GPa})$ & $v$ & $G(\mathrm{GPa})$ & $E(\mathrm{GPa})$ & $v$ & $G(\mathrm{GPa}$ \\
\hline 1826 & 100 & 100 & 0.291 & 33.13 & 900 & 70 & 200 & 150 & 0.250 & 72 & 100 & 0.07 & 40 \\
\hline 1673 & 73 & 97 & 0.286 & 33.89 & 750 & 72 & & & & & & & \\
\hline 1573 & 56 & 95 & 0.281 & 34.22 & 500 & 76 & & & & & & & \\
\hline 1473 & 36 & 92 & 0.272 & 34.47 & 300 & 78 & & & & & & & \\
\hline 1128 & 10 & 88 & 0.258 & 34.54 & & & & & & & & & \\
\hline 1118 & 0 & 86 & 0.251 & 34.50 & & & & & & & & & \\
\hline
\end{tabular}

${ }^{a}$ Compiled from Pabst et al. (2015)

${ }^{\mathrm{b}}$ Compiled from Mao et al. (2015)

${ }^{\mathrm{c}}$ Compiled from Ryan (1987)

${ }^{\mathrm{d}}$ Compiled from Yu et al. (2016) with $T>873 \mathrm{~K}$ (above $\alpha-\beta$ transition)

$K=\frac{1}{2 \bar{\nu}} \overline{\sum_{\text {contacts }} k_{\mathrm{c}} c_{i} c_{j}}=\frac{1}{2 \bar{\nu}} k_{\mathrm{c}} \frac{2 Z}{3} d^{2}$.

The modulus has a typical value in the order of $\varsigma\left(\Sigma / Q^{2}\right)^{1 / 3}$, where $\varsigma$ is a non-dimensional constant of order unity. Multiplying with the shear strain rate and integrating over a time $\Gamma$ gives the stress increase:

$\Gamma \varsigma\left(\Sigma / Q^{2}\right)^{1 / 3} \frac{\partial \dot{u}}{\partial y}$

For the material properties to change so that the medium becomes dilatant requires that this quantity approaches the pre-stress, so:

$\Gamma \approx \frac{1}{\varsigma}(Q \Sigma)^{2 / 3} \frac{1}{\frac{\partial \dot{u}}{\partial y}}$.

\section{References}

Amelung F, Jónsson S, Zebker H, Segall P (2000) Widespread uplift and 'trapdoor' faulting on Galápagos volcanoes observed with radar interferometry. Nature 407:993-996. https://doi. org/10.1038/35039604

Anderson AT, Swihart GH, Artioli G, Geiger CA (1984) Segregation vesicles, gas filter-pressing, and igneous Differentiation. J Geol 92:55-72. https://doi.org/10.1086/628834

Bachmann O, Bergantz GW (2004) On the origin of crystal-poor rhyolites extracted from batholithic crystal mushes. J Petrol 45:15651582. https://doi.org/10.1093/petrology/egh019

Bachmann O, Huber C (2018) The inner workings of crustal distillation columns; the physical mechanisms and rates controlling phase separation in silicic magma reservoirs. J Petrol 60:3-18. https:// doi.org/10.1093/petrology/egy103

Barriere M (1981) On curved laminae, graded layers, convection currents and dynamic crystal sorting in the Ploumanac' $h$ (Brittany) subalkaline granite. Contrib Mineral Petrol 77:214-224

Bea F, Fershtater GB, Montero P, Smirnov VN, Molina JF (2005) Deformation-driven differentiation of granitic magma: the Stepninsk pluton of the Uralides, Russia. Lithos 81:209-233
Bell F (2007) Engineering geology, 2nd edn. Butterworth-Heinemann, Oxford, p 592

Bergantz GW, Schliecher JM, Burgisser A (2017) On the kinematics and dynamics of crystal-rich systems. J Geophys Res Solid Earth 122:6131-6159. https://doi.org/10.1002/2017JB014218

Berger J, Lo K, Diot H, Triantafyllou A, Plissart G, Féménias O (2017) Deformation-driven differentiation during in situ crystallisation of the 2.7 Ma Iguilid mafic intrusion (West African Craton, Mauritania). J Petrol 58:819-840. https://doi.org/10.1093/petrology/ egx035

Biot MA (1941) General theory of three dimensional consolidation. J Appl Phys 12:155-164

Bowen NL (1920) Differentiation by deformation. Proc Nat Acad Sci 6:159-162

Bowen NL (1928) The evolution of the igneous rocks. Princeton University Press, Princeton, $\mathrm{p} 332$

Brown M, Rushmer T (1997) The role of deformation in the movement of granitic melt: views from the laboratory and the field. In: Holness MB (ed) Deformation enhanced fluid transport in the earth's crust and mantle. Chapman \& Hall, London, pp 111-144

Cai B, Karagadde S, Yuan L, Marrow TJ, Connolley T, Lee PD (2015) In situ synchrotron tomographic quantification of granular and intragranular deformation during semi-solid compression of an equiaxed dendritic Al-Cu alloy. Acta Mater 76:371-380. https ://doi.org/10.1016/j.actamat.2014.05.035

Carmichael ISE, Turner FJ, Verhoogen J (1974) Igneous petrology. McGraw-Hill, New York, p 739

Cashman KV, Sparks RSJ, Blundy J (2017) Vertically extensive and unstable crystals mushes: a unifying view of igneous processes associated with volcanoes. Science 355(6331):eaag3055. https ://doi.org/10.1126/science.aag3055

Christopher TE, Blundy J, Cashman K, Cole P, Edmonds M, Smith PJ, Sparks RSJ, Stinton A (2015) A Crustal-scale degassing due to magma system destabilization and magma-gas decoupling at Soufrière Hills Volcano, Montserrat. Geochem Geophys Geosyst 16:2797-2811. https://doi.org/10.1002/2015GC005791

Clemens JD, Petford N (1999) Granitic melt viscosity and silicic magma dynamics in contrasting tectonic settings. J Geol Soc Lond 156:1057-1060. https://doi.org/10.1144/gsjgs.156.6.1057

Clemens JD, Stevens G (2016) Melt segregation and magma interactions during crustal melting: breaking out of the matrix. Earth Sci Rev 160:333-349

Clemens JD, Watkins JM (2001) The fluid regime of high-temperature metamorphism during granitoid magma genesis. Contrib Mineral Petrol 140:600-606. https://doi.org/10.1007/s004100000205 
Clemens JD, Petford N, Mawer CK (1997) Ascent mechanisms of granitic magmas: causes and consequences. In: Holness M (ed) Deformation-enhanced fluid transport in the earth's crust and mantle. Chapman \& Hall, London, pp 144-171

Connolly JAD, Podladchikov YY (1998) Compaction-driven fluid flow in viscoelastic rock. Geodyn Acta 11:55-84

Donaldson CH, Henderson CMB (1988) A new interpretation of round embayments in quartz crystals. Mineral Mag 52:27-33

Emmons RC (1940) The contribution of differential pressures to magmatic differentiation. Am J Sci 238:1-21

Engelder T (1993) Stress regimes in the lithosphere. Princeton Press, Princeton, $\mathrm{p} 451$

Farina F, Stevens G, Villaros A (2012) Multi-batch, incremental assembly of a dynamic magma chamber: the case of the Peninsula pluton granite (Cape Granite Suite, South Africa). Mineral Petrol 106:193-216. https://doi.org/10.1007/s00710-012-0224-8

Floess D, Caricchi L, Simpson G, Wallis SR (2019) Melt segregation and the architecture of magmatic reservoirs: insights from the Muroto sill (Japan). Contrib Mineral Petrol 174:27. https://doi. org/10.1007/s00410-019-1563-9

Fonseca J, O'Sullivan C, Nagirac T, Yasuda H, Gourlay CM (2013) In situ study of granular micromechanics in semi-solid carbon steels. Acta Mater 61:4169-4179. https://doi.org/10.1016/j.actam at.2013.03.043

Geshi N (2001) Melt segregation by localised shear deformation and fracturing during crystallisation of magma in shallow intrusions of the Otoge volcanic complex, central Japan. J Volc Geotherm Res 106:285-300

Ghanbarian B, Hunt GA, Ewing RP, Sahimi M (2013) Tortuosity in porous media: a critical review. Soil Sci Soc Am J 77:1461. https ://doi.org/10.2136/sssaj2012.0435

Gottsmann J, Lavallée Y, Martí J, Aguirre-Díaz G (2009) Magmatectonic interaction and the eruption of silicic batholiths. Earth Planet Sci Lett 284:426-434. https://doi.org/10.1016/j. eps1.2009.05.008

Gourlay CM, Dhale AK (2007) Dilatant shear bands in solidifying metals. Nature 445:70-73. https://doi.org/10.1038/nature05426

Hillis R (2000) Pore pressure/stress coupling and its implications for seismicity. Explor Geophys 31:448-454

Hobbs BE, Means WD, Williams PF (1976) An outline of structural geology. Wiley International, New York, p 571

Hofmeister AM, Whittington AG, Pertermann M (2009) Transport properties of high albite crystals and near-endmember feldspar and pyroxene glasses and melts to high temperature. Contrib Mineral Petrol 158:381. https://doi.org/10.1007/s0041 0-009-0388-3

Holness MB (2018) Melt segregation from silicic crystal mushes: a critical appraisal of possible mechanisms and their microstructural record. Contrib Mineral Petrol 173:48. https://doi. org/10.1007/s00410-018-1465-2

Holness MB, Vukmanovic Z, Mariani E (2017) Assessing the role of compaction in the formation of adcumulates: a microstructural perspective. J Petrol 58:643-674

Huang N, Ovarlez G, Bertrand F, Rodts S, Coussot P, Bonn D (2008) Flow of wet granular materials. Phys Rev Lett 94:028301

Huber C, Parmigiani A (2018) A physical model for three-phase compaction in silicic magma reservoirs. J Geophys Res Sol EA 123:2685-2705. https://doi.org/10.1002/2017JB015224

Huber C, Bachmann O, Dufek J (2011) Thermo-mechanical reactivation of locked crystal mushes: melting-induced internal fracturing and assimilation processes in magmas. Earth Planet Sci Lett 304:443-454

Jackson MD, Blundy J, Sparks RSJ (2018) Chemical differentiation, cold storage and remobilization of magma in the Earth's crust. Nature 564:405-409. https://doi.org/10.1038/s41586-018-0746-2
Jaeger JC (1969) Fundamentals of rock mechanics. Methuen \& Co, London, p 513

Jaupart C, Tait S (1995) Dynamics of differentiation in magma reservoirs. J Geophys Res 100:17615-17636

Johnson KL (1985) Contact mechanics. Cambridge University Press, Cambridge. https://doi.org/10.1017/CBO9781139171731

Kareha K, O’Sullivan C, Nagira T, Yasuda H, Gourlay CM (2017) Dilatancy in semi-solid steels at high solid fraction. Acta Mater 125:187-195. https://doi.org/10.1016/j.actamat.2016.11.066

Karlstrom L, Rodolph ML, Manga M (2012) Caldera size modulated by the yield stress within a crystal-rich magma reservoir. Nature Geosci 5:402-405. https://doi.org/10.1038/NGO1453

Koenders MA (1997) A model of a granular assembly as a structured material. In: Proc. ASCE symp. on mechanics of deformation and flow of particulate materials. American Soc. of Civil Engineers, New York, pp 11-23

Koenders MA, Petford N (2000) Quantitative analysis and scaling of sheared granitic magmas. Geophys Res Lett 27:1231-1234

Koenders MA, Petford N (2005) Shear-induced pressure changes and seepage phenomena in a deforming porous layer-II. Geophys J Int 163:385-402. https://doi.org/10.1111/j.1365246X.2005.02719.x

Koenders MA, Petford N (2007) Shear-induced pressure changes and seepage phenomena in a deforming porous layer-III. Geophys J Int 171:943-953. https://doi.org/10.1111/j.1365246X.2007.03562.x

Kohlstedt DL, Holtzman BK (2009) Shearing melt out of the Earth: an experimentalist's perspective on the influence of deformation on melt extraction. Ann Rev Earth Planet Sci 37:561-593

Konishi J, Oda M, Nemat-Nasser S (1982) Inherent anisotropy and shear strength of assembly of oval cross-sectional rods. In: Vermeer PA, Luger HJ (eds) Proc. IUTAM conference on deformation and failure of granular materials, pp 403-412

Lerman A (1979) Geochemical processes: water and sediment environments. Wiley, New York, p 481

Lundstrom CC, Glazner AF (2016) Silicic magmatism and the volcanic-plutonic connection. Elements 12:91-96. https://doi. org/10.2113/gselements.12.2.91

Manga M, Castro KV, Cashman KV, Loewenberg M (1998) Rheology of bubble-bearing magmas: theoretical results. J Volc Geotherm Res 87:15-28

Mao Z, Fan D, Lin JF, Jang Y, Tkachev SN, Zhuravlev K, Prakapenka VB (2015) Elasticity of single-crystal olivine at high pressures and temperatures. Earth Planet Sci Lett 426:204-215. https://doi. org/10.1016/j.eps1.2015.06.045

Marsh DB (2002) On bimodal differentiation by solidification front instability in basaltic magmas part 1: basic mechanics. Geochemim Cosmochim Acta 66:2211-2229

Marsh DB (2004) A magmatic mush column Rosetta stone: the Mcmurdo dry valleys of Antarctica. EOS Trans Am Geophys Union 85:497-502

McBirney AR (1984) Igneous petrology. Freeman, San Francisco

McKenzie D (1984) The generation and compaction of partially molten rock. J Petrol 25:713-765

Mead WJ (1925) The geologic role of dilatancy. J Geol 33P:685-698

Meylan B, Terzi F, Gourlay G, Suery M, Dhale AK (2010) Development of shear bands during deformation of partially solid alloys. Scr Mater. https://doi.org/10.1016/j.scriptamat.2010.08.032

Pabst W, Gregorova E, Rambaldi E, Bignozzi MC (2015) Effective elastic constraints of plagioclase feldspar aggregates in dependence of the anorthite content-a concise review. Ceramics 59:326-330

Paterson SR, Ardill K, Vernon R, Zak J (2019) A review of mesoscopic magmatic structures and their potential for evaluating hypersolidus evolution of intrusive complexes. J Struct Geol 125:134-147 
Petford N (2009) Which effective viscosity? Miner Mag 73:167-191. https://doi.org/10.1180/minmag.2009.073.2.167

Petford N, Koenders MA (2003) Shear-induced pressure changes and seepage phenomena in a deforming porous layer-I. Geophys J Int 155:857-869. https://doi.org/10.1111/j.1365246X.2003.02076.X

Petford N, Mirhadizadeh S (2017) Image-based modelling of lateral magma flow: the Basement Sill, Antarctica. R Soc Open Sci 4:161083. https://doi.org/10.1098/rsos.161083

Petford N, Rushmer T, Yuen DA (2007) Deformation-induced mechanical instabilities at the core-mantle boundary. In: Hirose K, Brodholt J, Lay T, Yuen D (eds) Post-Perovskite: the last mantle phase transition. Geophys. Monograph, vol 174. American Geophysical Union, Washington, D.C, pp 271-287. 10.1029/174GM18

Pistone M, Arzilli F, Dobson KJ, Benoît C, Reusser E, Ulmer P, Marone F, Whittington AG, Mancini L, Fife JL, Blundy JD (2015) Gas-driven filter pressing in magmas: insights into in-situ melt segregation from crystal mushes. Geology 43:699-702. https:// doi.org/10.1130/G36766.1

Propach G (1976) Models of filter differentiation. Lithos 9:203-209. https://doi.org/10.1016/0024-4937(76)90038-4

Quintanilla-Terminel A, Dillman A, Pec M, Diedrich G, Kohlstedt DL (2019) Radial melt segregation during extrusion of partially molten rocks. Geochem Geophys Geosyst 20:2985-2996. https ://doi.org/10.1029/2018GC008168

Renner J, Evans B, Hirth G (2000) On the rheologically critical melt fraction. Earth Planet Sci Lett 181:585-594

Reynolds O (1885) On the dilatancy of media composed of rigid particles in contact. With experimental illustration. Philos Mag 20:469-481

Rosenberg CL, Handy MR (2005) Experimental deformation of partially melted granite revisited: implications for the continental crust. J Metamorph Geol 23:19-28

Rudnicki JW, Rice JR (1975) Conditions for the localisation of deformation in pressure-sensitive dilatant materials. J Mech Phys Solids 23:371-394

Rust AC, Manga M, Cashman KV (2003) Determining flow type, shear rate and shear stress in magmas from bubble shapes and orientations. J Volc Geotherm Res 122:111-132

Rutter EH, Neumann DHK (1995) Experimental deformation of partially molten Westerly granite under fluid-absent conditions, with implications for the extraction of granitic magmas. J Geophys Res 100:15697-15715

Ryan MP (1987) Volcanism in Hawaii. The elasticity and contractancy of Hawaiian olivine tholeiite and its role in the stability and structural evolution of subcaldera magma reservoirs and rift systems. US Geol Surv Prof Pap 1350:1395-1447

Ryerson JF, Weed HC, Piwinskii AJ (1988) Rheology of subliquidus magmas: 1. Picritic compositions. J Geophys Res Solid Earth 93:3421-3436. https://doi.org/10.1029/JB093iB04p03421

Schall P, Hecke M (2009) Shear bands in matter with granularity. Ann Rev Fluid Mech 42:67-88. https://doi.org/10.1146/annurev-fluid $-121108-145544$

Scott DR, Stevenson DJ (1986) Magma ascent by porous flow. J Geophys Res Solid Earth 91:9283-9296

Shaw HR (1980) The fracture mechanisms of magma transport from the mantle to the surface. In: Hargraves RB (ed) Physics of magmatic processes. Princeton University Press, Princeton, pp 201-264

Sheikh-Ansari MH, Aghaie-Khafri M (2018) Shear localization in semi-solid deformation: a bifurcation theory approach. Mech Res Commun 89:1-5. https://doi.org/10.1016/j.mechrescom .2018 .02 .002

Shi X, Polycarpou AA (2005) Measurement and modelling of normal contact stiffness and contact damping at the mesoscale. J Vib Acoust 127:52-60. https://doi.org/10.1115/1.1857920
Sisson TW, Bacon CR (1999) Gas-driven filter pressing in magmas. Geology 27:613-616

Smith JV (1997) Shear thickening dilatancy in crystal-rich flows. J Volc Geotherm Res 79:1-8

Solano JM, Jackson MD, Sparks RSJ, Blundy JD, Annen C (2012) Melt segregation in deep crustal hot zones: a mechanism for chemical differentiation, crustal assimilation and the formation of evolved magmas. J Petrol 53:1999-2026. https://doi.org/10.1093/petro logy/egs041

Sparks RSJ, Annen C, Blundy JD, Cashman KV, Rust AC, Jackson MD (2019) Formation and dynamics of magma reservoirs. Philos Trans R Soc Lond 377(2139):20180019. https://doi.org/10.1098/ rsta.2018.0019

Stevenson DJ (1989) Spontaneous small scale melt segregation in partial melts undergoing deformation. Geophys Res Lett 16:1067-1070

Su TC, O'Sullivan C, Nagira T, Yasuda H, Gourlay CM (2019) Semisolid deformation of $\mathrm{Al}-\mathrm{Cu}$ alloys: a quantitative comparison between real-time imaging and coupled LBM-DEM simulations. Acta Mater 163:208-225. https://doi.org/10.1016/j.actam at.2018.10.006

Tait SR, Jaupart C (1992) Compositional convection in a reactive crystalline mush and melt differentiation. J Geophys Res 97:6735-6756

Terzaghi K (1943) Theoretical soil mechanics. Wiley, New York, p 510

Thornton C, Sun G (1993) Axisymmetric compression of 3D polydisperse systems of spheres. Powders Grains 93:129-134

Turcotte DL, Schubert G (2002) Geodynamics, 2nd edn. Cambridge University Press, Cambridge, p 456

van der Molen I, Paterson MS (1979) Experimental deformation of partially melted granite. Contrib Mineral Petrol 70:299-318

Vigneresse J-L, Barbey P, Cuney M (1996) Rheological transitions during partial melting and crystallization with application to felsic magma segregation and transfer. J Petrol 37:1579-1600

Wakeman RJ, Tarleton ES (2005) Solid/liquid separation principles of industrial filtration. Elsevier Advanced Technology, Amsterdam, p 339

Walte NP, Rubie DC, Bons PB, Frost DJ (2011) Deformation of a crystalline aggregate with a small percentage of high-dihedralangle liquid: implications for core-mantle differentiation during planetary formation. Earth Planet Sci Lett 305:124-134. https:// doi.org/10.1016/j.epsl.2011.02.049

Waters LE, Lange RA (2017) Why aplites freeze and rhyolites erupt: controls on the accumulation and eruption of high- $\mathrm{SiO}_{2}$ (eutectic) melts. Geology 45(11):1019-1022

Weinberg RF, Veveakis E, Regenauer-Lieb K (2015) Compactiondriven melt segregation in migmatites. Geology 43:471-474. https://doi.org/10.1130/G36562.1

Wiebe R (1993) The Pleasant Bay layered gabbro-diorite, coastal Maine: ponding and crystallization of basaltic injections into a silicic magma chamber. J Petrol 34:461-489

Yu C, Ji S, Li Q (2016) Effects of porosity on seismic velocities, elastic moduli and Poisson's ratios of solid materials and rocks. J Rock Mech Geotech Eng 8:35-49. https://doi.org/10.1016/j.jrmge .2015 .07 .004

Zhang Y, Ni H (2010) Diffusion of H, C, and O components in silicate melts. Rev Mineral Geochem 72:171-225. https://doi. org/10.2138/rmg.2010.72.5

Zimmerman ME, Kohlstedt DL (2004) Rheological properties of partially molten lherzolite. J Petrol 45:275-298. https://doi. org/10.1093/petrology/egg089

Publisher's Note Springer Nature remains neutral with regard to jurisdictional claims in published maps and institutional affiliations. 